\title{
ZIF-C as non-viral delivery system for CRISPR/Cas9 mediated hTERT knockdown in cancer cells
}

Suneela Pyreddy, ${ }^{[a]}$ Arpita Poddar, ${ }^{[a]}$ Francesco Carraro, ${ }^{[b]}$ Shakil Ahmed Polash, ${ }^{[a]}$ Chaitali Dekiwadia, ${ }^{[a]}$ Zeyad Nasa, ${ }^{[a]}$ T. Srinivasa Reddy, ${ }^{[a]}$ Paolo Falcaro ${ }^{*[b]}$, Ravi Shukla *[a]

[a] S. Pyreddy, A. Poddar, S.A. Polash, Dr. C. Dekiwadia, Dr. S.R. Telukutla, Dr. R. Shukla*

Centre for Advanced Materials \& Industrial Chemistry, School of Science

RMIT University

Melbourne, Victoria 3001, Australia.

[b] Dr. F. Carraro, Dr. P. Falcaro*

Institute of Physical and Theoretical Chemistry Graz University of Technology

Graz 8010, Austria.

Abstract: Telomerase, a ribonucleoprotein coded by the hTERT gene, plays an important role in cellular immortalization and carcinogenesis. hTERT is a suitable target for cancer therapeutics as its activity is highly upregulated in $85-90 \%$ of cancer cells but absent in normal somatic cells. Here, we target the hTERT gene at the DNA level by applying the Clustered Regularly Interspaced Short Palindromic Repeat (CRISPR)/Cas9 technology encapsulated in a recently discovered Metal-Organic Framework (MOF). We show that the MOF subtype 'ZIF-C' can efficiently load the hTERT targeting CRISPR system (CrhTERT@ZIF-C) and protect it from enzymatic degradation. The CrhTERT@ZIF-C is endocytosed by cancer cells and successfully disrupts the hTERT gene. The resultant inhibition of hTERT decreases cellular proliferation and causes apoptotic cancer cell death. Furthermore, hTERT knockdown shows a significant reduction in tumor metastasis and alters protein expression. Thus, our results conclusively establish ZIF-C based targeting of hTERT as a highly promising and novel approach for gene therapy in cancer.

\section{Introduction}

In normal conditions, cells proliferate for a certain number of divisions until they reach a critical threshold called the Hayflick limit, followed by an irreversible cellular senescence. ${ }^{[1]}{ }^{[2]}$ The Hayflick limit is determined by the length of nucleotide sequences called telomeres (repeats of TTAGGG sequence present at the end of eukaryotic chromosomes) ${ }^{[3]}$ that continuously shorten after every successive cell division event (see Figure 1 a-c). In cancer cells, the anomalous presence of telomerase, a ribonucleoprotein enzyme, maintains telomere lengths indefinitely and cells undergo uncontrolled replication to gain immortalization (see Figure 1d). ${ }^{[4]}{ }^{[5]}{ }^{[5 b]}$ Hence, high telomerase activity is considered a hallmark of oncogenesis, with enhanced activity in a wide range of malignancies including liver, prostate, breast, colon, and pancreatic cancers. ${ }^{[4][6]}$

Human telomerase is coded by the human telomerase reverse transcriptase (hTERT) gene ${ }^{[7]}{ }^{[8]}$ that has been targeted with successful inhibition of cancer cell proliferation. ${ }^{[9] ~[10] ~[11] ~[12] ~ I n ~ t h i s ~ s t u d y, ~ w e ~ t a r g e t ~ h T E R T ~ g e n e ~ b y ~}$ using a CRISPR (clustered regularly interspaced short palindromic repeats) /Cas9 system encapsulated in a Metal- 
Organic Framework (MOF) carrier (see Figure 1d-g). CRISPR/Cas9 is an adaptive immune system employed for genomic editing in human cells. ${ }^{[13]}{ }^{[14]}$ This system uses a short guide RNA (gRNA) complementary to target DNA, which forms a complex with the Cas9 endonuclease and induces a DNA double-stranded break (DSB) to target genomic region. ${ }^{[15]}$ Due to its high specificity, simplicity, high efficiency, and economic nature compared with other gene editing systems like zinc-finger nucleases (ZFNs) and transcription activator-like effector nucleases (TALENs), CRISPR/Cas9 system gained furious pace in molecular genetics. ${ }^{[16]}$ The major concern in CRISPR/Cas9 system is the intracellular delivery; traditional methods based on viral vectors continue to show significant safety issues and provide insufficient data regarding long term use. ${ }^{[17]}$ Physical methods like electroporation and microinjection have also been reported but their in vivo use is limited because of their complicated invasive nature. ${ }^{[18]}$ Different non-viral vectors have been explored for the delivery of CRISPR/Cas9 systems, proving that synthetic materials can be employed as safe and inexpensive carriers. ${ }^{[19]}$ [20] [21] [17] [19b] [22]

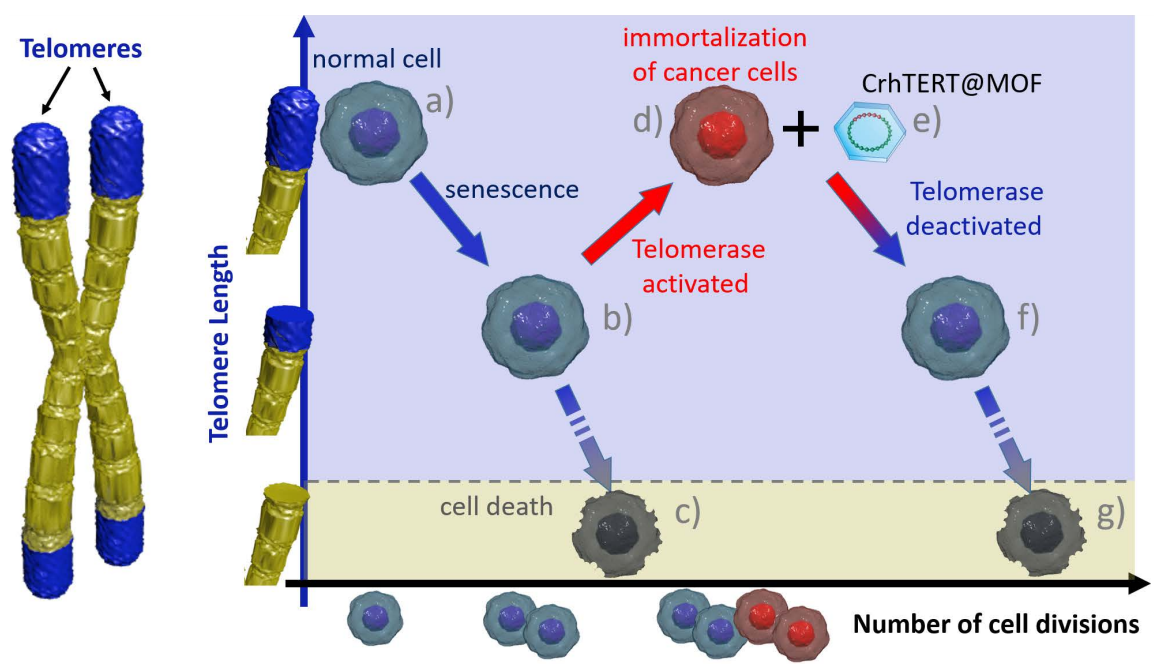

Figure 1. Schematic representation of location of telomeres, function of telomerase in normal and cancer cells and effect of CrhTERT@MOF biocomposite on telomerase.

In this context, MOF materials emerged as a promising non-viral vector system for gene therapy. ${ }^{[23]}$ The most studied MOF for this application is Zeolitic Imidazolate Framework-8 (ZIF-8), an extended material based on $\mathrm{Zn}^{2+}$ and 2-methylimidazole $\left(\mathrm{Zn}(2-\mathrm{m} / \mathrm{m})_{2}\right)$ that possess sodalite topology (sod, space group: $\left.1-43 \mathrm{~m}\right)$ and can selfassemble around proteins in bio-compatible conditions. ${ }^{[24]}{ }^{[25]}$ We recently found that the same building blocks in presence of carbonate anions and biomolecules can lead to the formation of a different MOF named ZIF-C $\left(\mathrm{Zn}_{2}(2-\mathrm{mlm})_{2}\left(\mathrm{CO}_{3}\right)\right.$, space group: Pba2). ${ }^{[26][27]}$

We previously demonstrated that ZIF-C is a promising delivery system of CRISPR/Cas9 for targeting the RPSA gene for prostate cancer. ${ }^{[27]}$ In the present work, through an aqueous-based one-pot encapsulation, we synthesized both ZIF-C and ZIF-8 loaded with the CRISPR/Cas9 plasmid system ( $9.2 \mathrm{kbp}$ ) targeting the hTERT (CrhTERT) gene. Remarkably, CrhTERT@ZIF-C showed a higher encapsulation efficiency (EE\%) of 85\% when compared to the corresponding ZIF-8 biocomposites (CrhTERT@ZIF-8, EE\% 58\%). Based on the relevance of EE\%, ${ }^{[24]}$ ZIF-C was 
selected as the non-viral vector and CrhTERT@ZIF-C was subsequently characterized to study the morphology and stability of the encapsulated plasmid against enzymatic degradation. The transfection efficiency and cellular uptake of CrhTERT@ZIF-C on prostate cancer cells (PC-3) were examined. The genomic editing efficiency of CrhTERT@ZIF-C on PC-3 was determined by genomic cleavage detection assay and we observed approximately 19\% indel efficiency. The knockdown efficiency of CrhTERT@ZIF-C by quantitative polymerase chain reaction (qPCR) was also determined in different cell lines such as: PC-3, Cervical cancer cells (HeLa) and Breast cancer cells (MCF7). After treatment with CrhTERT@ZIF-C, we observed a significant decrease in the hTERT expression in all three different cancer cells. Finally, the effect of genomic editing of hTERT on cell proliferation, apoptosis, tumor metastasis and protein expression in vitro were also examined.

\section{Results and Discussion}

In order to synthesize target specific CRISPR/Cas9 system against hTERT, Cas9 plasmids containing gRNAs specific to hTERT were generated (Figure S1A). The plasmid constructs were sequence verified and selected for synthesis of CrhTERT@MOF.

The synthesis of CrhTERT@MOF was performed via one-pot encapsulation. In a typical experiment, an aqueous solution containing $100 \mu \mathrm{L}$ of 2-methylimidazole (2-mIm) and CrhTERT ( $3 \mu \mathrm{g}$, see SI for plasmid synthesis details) were mixed with $100 \mu \mathrm{L}$ of an aqueous solution of zinc acetate (40 mM) and incubated for $10 \mathrm{~min}$ at room temperature. The solution changed immediately from transparent to cloudy indicating the rapid formation of particles. After incubation, the pellet was collected by centrifugation and washed thrice with water at $10000 \mathrm{rcf}$ for $10 \mathrm{~min} .{ }^{[28]}$ The ligand to metal molar ratio (L:M) was optimized to obtain biocomposites with ZIF-C and sodalite ZIF-8 crystal structures. Ratios of L:M=4 and L:M=64 were used to prepare ZIF-C and ZIF-8 (sod), respectively (Figure 2A). The crystal structures of the powdery biocomposites were examined by $x$-ray diffraction (XRD). The diffraction patterns plotted in Figure $\mathbf{2 B}$ are ascribed to ZIF-C $\left((110)=11.05^{\circ}, \quad(200)=14.4^{\circ}, \quad(120)\right.$ $\left.=16.7^{\circ},(200)=16.8^{\circ},(210)=18.3^{\circ}\right)$ when the L:M is 4 and to sod ZIF-8 $\left((110)=7.35^{\circ},(200)=10.4^{\circ},(211)=12.8^{\circ}\right.$, $\left.(310)=16.5^{\circ},(222)=18.1^{\circ}\right)$ when the L:M is $64 .^{[29]}$ The chemical compositions of the biocomposites were investigated via IR spectroscopy. The FTIR spectra (Figure S2) confirmed the presence of the typical vibrational bands of ZIF-C and ZIF-8, respectively for $L: M=4$ and $L: M=64 .{ }^{[24]}$ 
A

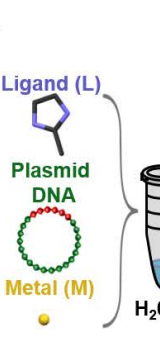

D

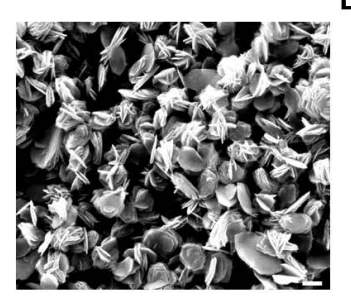

B
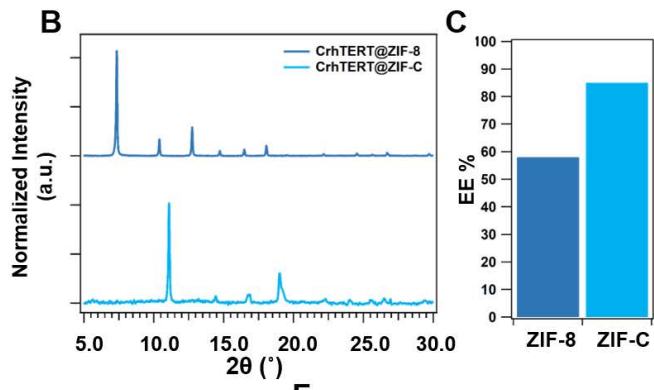

$F$
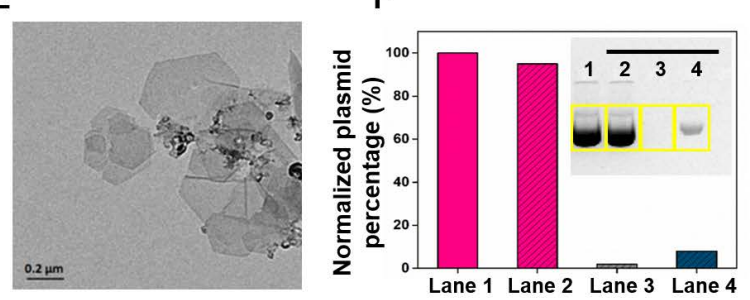

Figure 2. Synthesis and characterization. (A) Schematic representation of synthesis of CrhTERT encapsulated ZIF-C and sod ZIF-8. (B) Powder X Ray Diffraction (PXRD) patterns of CrhTERT@ZIF-C and CrhTERT@ZIF-8. (C) Encapsulation efficiency of CrhTERT@ZIF-C and CrhTERT@ZIF-8 by agarose gel electrophoresis. The EE\% was calculated using densitometry analysis by ImageJ software. (D) Scanning electron microscopy image, scale bar $1 \mu \mathrm{m}$. (E) Transmission electron microscopy image of CrhTERT@ZIF-C, scale bar $0.2 \mu \mathrm{m}$ (F) Protection assay to determine the integrity of CrhTERT inside the ZIF-C. Insert: The agarose gel electrophoresis image where Lane 1: CrhTERT@ZIF-C without DNase I treatment, Lane 2: CrhTERT@ZIF-C treated with DNase, Lane 3: CrhTERT+ZIF-C treated with DNase and Lane 4: CrhTERT treated with DNase.

In general, in drug delivery systems, the encapsulation efficiency (EE) is a relevant parameter. ${ }^{[24]}$ For the delivery of nucleic acids, EE\% indicates the efficiency of gene therapy vector. ${ }^{[30]}$ While prior works assessed EE\% of alcoholbased synthesis of ZIF-8, we chose an aqueous synthesized ZIF-8 in order to follow physiologically compatible preparation methods. Thus, we examined the EE\% of ZIF-C and ZIF-8 by analyzing the amount of CrhTERT in CrhTERT@ZIF-C and CrhTERT@ZIF-8. The biocomposites were digested with 20mM EDTA to dissolve the MOF structure, ${ }^{[31]}$ and run on an agarose gel electrophoresis to quantify the amount of released plasmid. As observed in Figures 2C and S3, the plasmid bands obtained from the dissolved CrhTERT@ZIF-C and CrhTERT@ZIF-8 correspond to the untreated control CrhTERT plasmid. Based on the densitometry analysis of the bands, the CrhTERT loading capacity is $85 \%$ and $58 \%$ for ZIF-C and ZIF-8, respectively. The analyses of the supernatants confirm that residual plasmid is present in both solution and in larger amount in case of the ZIF-8 synthesis (Figure S3). This confirms the higher EE\% of ZIF-C. This was reconfirmed using Fluorescence spectroscopy (Figure S4).

The performed characterizations confirm the synthesis of CrhTERT@ZIF-C and CrhTERT@ZIF-8 biocomposites. It should be noted that in the absence of CrhTERT, no solid material was recovered when L:M = 4 was used (for the same reaction time), suggesting the formation of CrhTERT@ZIF-C via biomimetic mineralization. [24] Based on the superior EE\%, CrhTERT@ZIF-C was selected for further investigations and in vitro studies.

The morphology of the CrhTERT@ZIF-C particles was studied by scanning electron microscopy (SEM) (Figure 2D) and transmission electron microscopy (TEM) (Figure 2E). The SEM shows plate-like particles with average size of 
$1.0 \pm 0.2 \mu \mathrm{m}$ and ca. $70 \mathrm{~nm}$ thickness. TEM images show that the CrhTERT@ZIF-C particles are made of aggregated hexagonal crystalline plates.

To accomplish successful transfection and ensure cellular delivery, an ideal carrier should protect the encapsulated DNA from serum nuclease degradation. [32] For CrhTERT@ZIF-C, DNA protection was verified using DNase I, a model endonuclease enzyme. As shown in Figure $2 \mathrm{~F}$, the endonuclease degraded free CrhTERT in aqueous solution (control sample). CrhTERT mixed with pre-synthesized ZIF-C particles (CrhTERT+ZIF-C) also degraded showing that surface immobilization does not provide protection against the endonuclease enzyme. Conversely, CrhTERT@ZIF-C exposed to DNase I shows the full preservation of encapsulated DNA. Thus, ZIF-C serves as an excellent material for nucleic acid preservation because of the high EE\% and significant protection of the encapsulated CrhTERT.

As the microenvironment of cancer cells is typically acidic, [33] in silico release of CrhTERT from CrhTERT@ZIF-C was assayed under acidic and normal physiological pH conditions to simulate cancer cell microenvironment. Fluorescence spectrophotometry was used to investigate the release profile of CrhTERT@ZIF-C in phosphate buffer saline (PBS) solution at pH 5.2 and 7.4. As observed in Figure S5, under physiological conditions of pH 7.4, there is a minor release of CrhTERT in $24 \mathrm{~h}(<15 \%)$, likely due to the decomposition effect induced by the phosphate ions of PBS. [34] Whereas, under acidic conditions of pH 5.2, the ZIF-C matrix starts releasing a significant amount of CrhTERT from $0.5 \mathrm{~h}(32 \%)$ with a $55 \%$ release of the encapsulated DNA at $24 \mathrm{~h}$. This indicates that CrhTERT@ZIF-C has sufficient stimuli-responsive properties for the triggered release of plasmid DNA preferentially within intracellular environment.

To assess cellular delivery over time, fluorescently labelled CrhTERT (Y-CrhTERT) was encapsulated to synthesize fluorescent Y-CrhTERT@ZIF-C biocomposites. Following cell transfections, green fluorescence was recorded to measure cellular uptake of Y-CrhTERT@ZIF-C up to 24-hour time points using fluorescence microscopy and a flow cytometry. Fluorescence images (Figure 3A) revealed that Y-CrhTERT@ZIF-C are localized on the cell membrane and in the cytoplasmic compartments at $3 \mathrm{~h}, 6 \mathrm{~h}$ and $24 \mathrm{~h}$. Fluorescence was observed closer to the nuclei at longer time points, indicating their gradual intracellular movement towards the nucleus. Upon quantification 

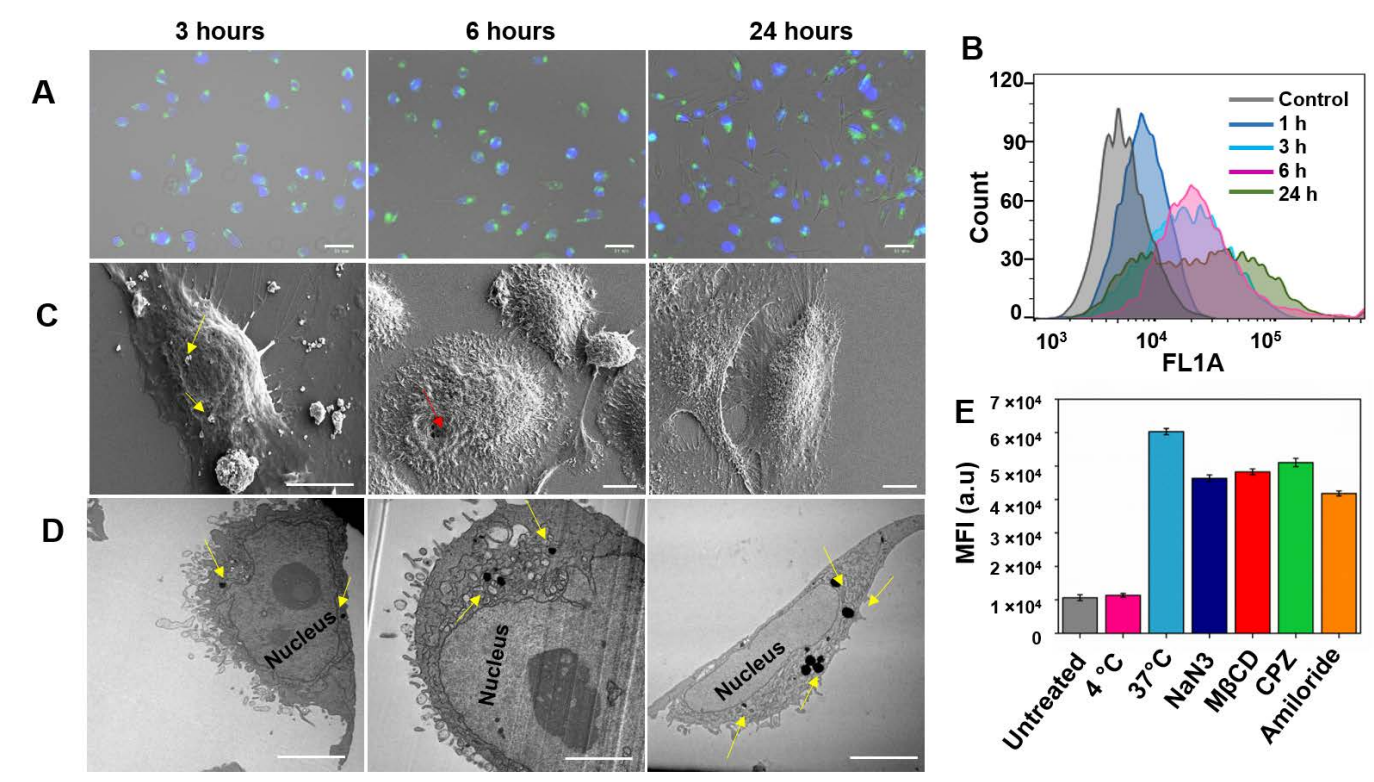

Figure 3. Cellular internalization and mechanism of uptake, gene delivery from CrhTERT@ZIF-C. PC-3 cells were treated with CrhTERT@ZIF$\mathrm{C}$ and tracked for localization at different time points using (A) Fluorescence microscopy images, where CrhTERT was labelled by YOYO-1 and stained the nuclei with Hoechst 33342 stain. Scale bar $50 \mu \mathrm{m}$. (B) Histogram plot of quantification of Y-CrhTERT@ZIF-C uptake by BDAccuri C6 flow cytometry. Data is analyzed using Flowjo software (C) Scanning electron microscopy images, scale bar $10 \mu \mathrm{m}$. (D) Transmission electron microscopy images, scale bar $2 \mu \mathrm{m}$. (E) Study on the mechanism of cellular uptake of CrhTERT@ZIF-C using Flow cytometry.

using flow cytometry (Figure 3B), the fluorescence intensity (FL1A) plot curves shift to the right, indicating particle interaction with cells. The concomitant increase in mean fluorescence intensity up to ca. $45 \%$ with time clearly indicates particle uptake. Similarly, SEM and TEM images confirm the cellular internalization of CrhTERT@ZIF-C. SEM images (Figure $3 \mathrm{C}$ ) of $3 \mathrm{~h}$ treated cells show biocomposites adhered to the cell surface. A number of submicron sized pits on the cell surface could be observed up to $6 \mathrm{~h}$ followed by attainment of normal surface topology by $24 \mathrm{~h}$. These data suggest a rather slow entry (uptake) of the biocomposites intracellularly. Furthermore, TEM visualization of CrhTERT@ZIF-C (Figure 3D) reveals localization of these biocomposites inside the cell, coinciding with the results obtained from fluorescence imaging. CrhTERT@ZIF-C particles are found to be localized within the vesicles and in the cytoplasm. None of the particles were visualized within the nucleus, suggesting CrhTERT is released from ZIF-C in the cytoplasm before translocating to nucleus. These finding are consitent with previous reports on similar particle localization within the cells. [28] The presence of peripheral exosomes and high number of intracelluar vesicles with larger nuclei are general characteristics of highly metabolic cancer cells. These data along with the integrity of cell membranes and nuclear morphology suggest that CrhTERT@ZIF-C are uptaken by the cells with a negligible toxic impact on cellular architecture.

Following confirmation of uptake, mechanistic studies using endocytosis pathway inhibitors were subsequently performed to ascertain mode of entry. Cells were pre-treated with non-toxic inhibitory concentrations of chlorpromazine (CPZ), methyl- $\beta$-cyclodextrin $(\mathrm{M} \beta C D)$, amiloride and sodium azide (NaN3) to block clathrin, caveolae, macropinocytosis and energy-dependent endocytosis, respectively. [35] Cellular uptake of $\mathrm{Y}$ - 
CrhTERT@ZIF-C in presence of inhibitors is shown in Figure 3E and Figure S6. Incubation of cells with the biocomposites at $4^{\circ} \mathrm{C}$ significantly impeded uptake as compared to $37^{\circ} \mathrm{C}$ controls; indicating cellular uptake of these particles is through an active process and requires physiological temperature. [36] Further, the reduction in cell uptake to ca. $75 \%$ by NaN3, ca. $80 \% \mathrm{MBCD}, 85 \%$ by $\mathrm{CPZ}$ and ca. $70 \%$ in amiloride compared to untreated cells is observed. These results imply that the cellular uptake of Y-CrhTERT@ZIF-C involves multiple endocytosis pathways. These findings further corroborate with microscopy data wherein particles are found within and outside the vesicles in the cytoplasm at earlier time points.

Next, we examined the transfection efficiency and gene editing capacity of CrhTERT@ZIF-C on cancer cells. Intracellular distribution and subcellular localisation of Y-CrhTERT@ZIF-C in lysosomes were assessed. As shown in Figure S7, Y-CrhTERT@ZIF-C green fluorescence can be seen overlapping with the LysoTracker (red) stained endosomes after $3 \mathrm{~h}$ treatment. Later at $6 \mathrm{~h}$ treatment, significant separation of red and green fluorescence can be seen, indicating release of CrhTERT from endosomes. Protonation of imidazole ring can account for the observed endosomal escape. ${ }^{[37]}$ The endosomal escape of the carrier plays a vital role in cargo delivery. The successful carrier should overcome the entrapment and degradation in endosomal vesicles, in order to achieve cytosolic availability of the cargo biomolecules. ${ }^{[38]}$ The proposed mechanism for cellular gene delivery and knockdown from CrhTERT@ZIF-C is illustrated in Figure 4A.

Briefly, the constructed CRISPR/Cas9 plasmid has a gene region coding for orange fluorescence protein (OFP) Figure S1. When successfully transfected, cells transcribe the OFP gene to express the protein that can be detected with fluorescence signal $\left(\lambda_{\mathrm{OFP}}=560 \mathrm{~nm}\right)$. Thus, transfection results were monitored using both fluorescence microscopy and flow cytometry. In CrhTERT@ZIF-C treated cells, the OFP detection was slow and gradual, similar to prior results. ${ }^{[27]}$ The orange fluorescence starts to appear in prolonged time over $96 \mathrm{~h}$ in CrhTERT@ZIF-C treated cells when compared to a gold standard Lipofectamine 3000 positive control, which shows normally in $24 \mathrm{~h}$. As shown in Figure 4C the CrhTERT@ZIF-C resulted in significant amount of OFP expression at $96 \mathrm{~h}$ indicating a slower release of CrhTERT. These results correspond to ca. $30 \%$ transfection efficiency when compared with the positive control (Figure S8).

The genome editing efficiency of CrhTERT@ZIF-C was further assessed using GeneArt Genomic Cleavage Detection Kit where Cas9-induced indel mutation in the genome was detected by the detection enzyme and visualized by running the product on an agarose gel electrophoresis (indel \%). As shown in Figure 4E, the presence of cleaved bands on treatment with CrhTERT@ZIF-C indicates that gene editing was successfully carried out by ZIF-C as the delivery vehicle. The percentage of indel efficiency was determined by densitometry analysis of the agarose gel. When compared with Lipofectamine 3000, Indel efficiency of CrhTERT@ZIF-C was found to be ca. $20 \%$. 
A

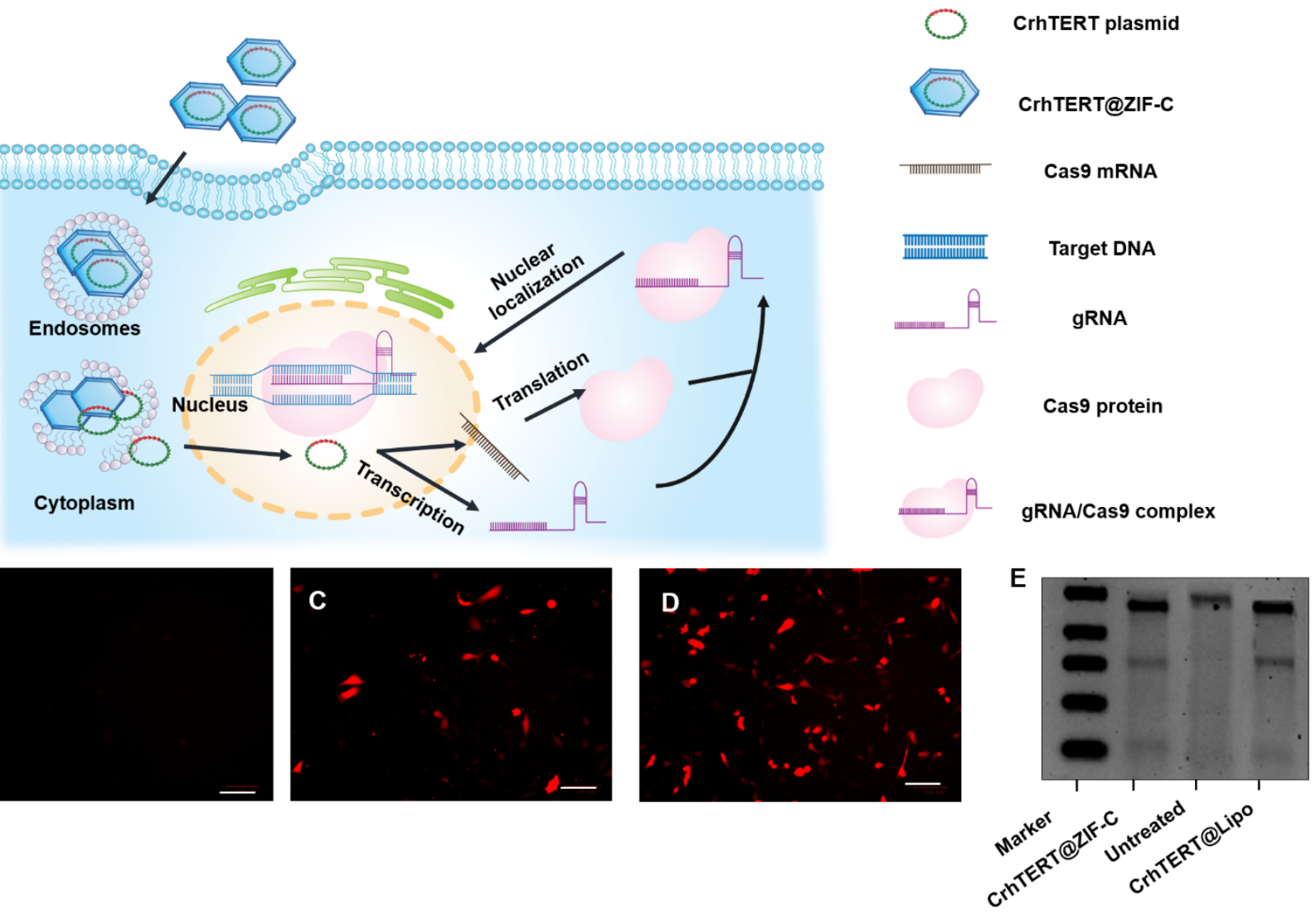

Figure 4. Gene delivery and gene editing of CrhTERT@ZIF-C . (A) Schematic representation of intercellular uptake and mechanism of gene editingCrhTERT@ZIF-C. After endosomal escape, plasmid will be delivered into nucleus and transcribe the gene into Cas9 mRNA. mRNA transport to cytoplasm where it translated into protein and form a complex with gRNA of hTERT. Then complex then transport back to nucleus where CRISPR mechanism exert its effect on targeted genomic DNA. (B-D) Fluorescence microscopy images of transfection assay. Orange fluorescence due to protein expression from CrhTERT. (B) Untreated cells (C) CrhTERT@ZIF-C treated cells and (D) CrhTERT complexed with Lipofectamine 3000 reagent. Scale bar $100 \mu \mathrm{m}$. Images are taken at $96 \mathrm{~h}$. (E) hTERT genomic cleavage detection determined from 2\% agarose gel electrophoresis. For comparison, the cells treated by CrhTERT@ZIF-C with untreated cells as control and lipofectamine 3000 plasmid complex were studied.

Next, to study the generality of hTERT gene knockdown approach and applicability of CrhTERT@ZIF-C in cancer cells, the expression of hTERT was determined by quantitative Polymerase Chain Reaction (qPCR) in prostate (PC3), cervical (HeLa), and breast (MCF7) cancer cells. As evident in Figure 5A cancer cells have several folds higher mRNA expression of hTERT when compared to normal prostate (PNT1a) cells. qPCR was performed to quantify the mRNA level of hTERT in cells treated with CrhTERT@ZIF-C and the CT values are normalized with the untreated cells. The results show that hTERT expression level is significantly inhibited by when compared to the untreated cells (Figure 5B). These results demonstrate knockdown of hTERT mRNA expression in PC-3 cells by ca.12\%, HeLa by ca. $25 \%$ and MCF7 by ca. $20 \%$. 
Following determination of hTERT knockdown, we studied the impact of the knockdown on cell viability and cell proliferation. hTERT has an integral function in tumorigenesis by means of adjusting cell proliferation, promoting the antiapoptotic protein, and inhibiting the apoptotic proteins. ${ }^{\left[{ }^{39]}\right.}$ The effect of hTERT knockdown on cell viability was studied by MTT assay on both normal cells and cancerous cells. Both the cells were treated with CrhTERT@ZIF-C for 24 and 96 h. Cells treated with pure ZIF-C were used as vehicle control. Figure 5C shows that cells exposed to pure ZIF-C retained $80 \%$ viability up to $96 \mathrm{~h}$; this confirms that the delivery system itself does not play a significant role in cell growth inhibition. When cancer cells were exposed to CrhTERT@ZIF-C, the viability decreased to ca. $57 \%$ in PC-3, 50\% in Hela, and 58\% in MCF-7 cells by 96 h. In contrast normal cells (control) exhibit a ca. 75\% viability. This demonstrates that the cell growth inhibition by CrhTERT@ZIF-C induced by hTERT knockdown is significantly higher in cancer cells than in normal cells. Besides, the cell growth inhibitory effect of hTERT knockdown is weaker in PNT1a cells than in other cancer cells. This is due to the lower hTERT expression in PNT1a cells than that of other cancer cells.

Migration of cancer cells plays a key role in tumour metastasis and measurement of migration capacity can be correlated with the metastatic potential. ${ }^{[40]}$ The impact of hTERT knockdown on cell migration was thus assessed. As demonstrated in Figure 5D, migration patterns of PC-3, HeLa and MCF7 cells treated with CrhTERT@ZIF-C was compared to untreated cells. The results show a ca. $43 \%, 40 \%$ and $51 \%$ decrease in migration of treated cells, respectively, as compared to untreated cells.

In addition, clonogenic cell survival assay was performed to investigate the long-term cytotoxicity of the CrhTERT@ZIF-C. PC-3, HeLa and MCF7 cells exposed to the CrhTERT@ZIF-C shows ca. 50\%, 48\% and 44\% inhibition in the colony formation when compared with the untreated control, indicating that hTERT down regulation can hinder growth and proliferation (Figure 5E). This can be attributed to the lack of hTERT protein to bind the NF-KB targeted genes like interleukin-6 (IL-6) ${ }^{[41]}$ which enhance the cancer cell migration by activating the enzymes required for cell movement. 

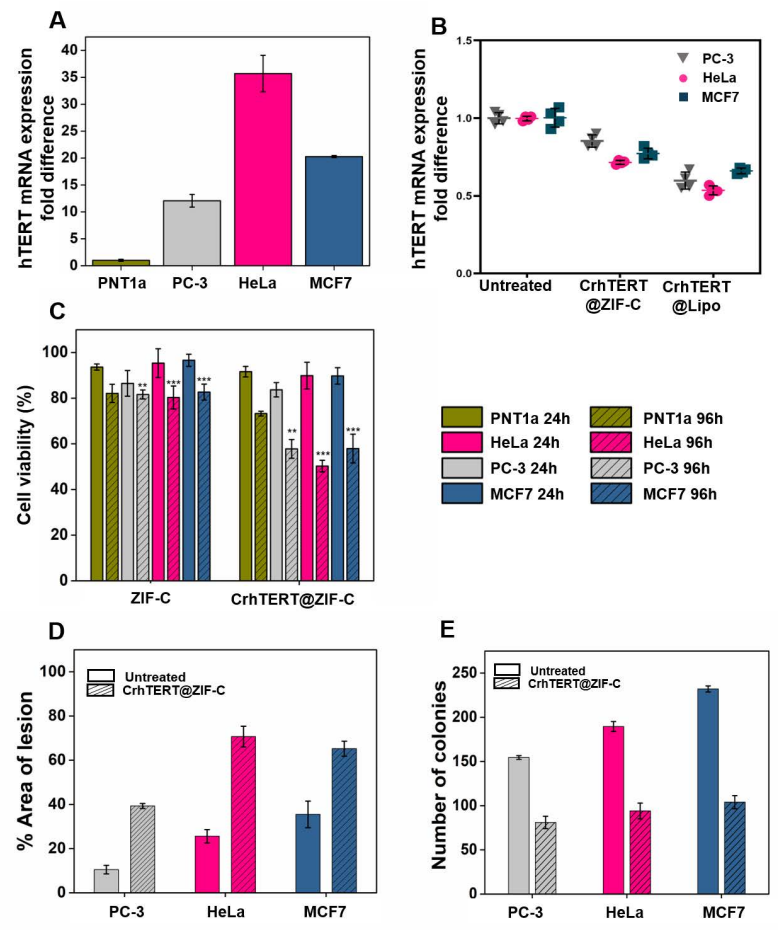

Figure 5. (A) hTERT mRNA expression in Prostate cancer cells (PC-3), cervical cancer cells (HeLa) and breast cancer cells (MCF7) compared with non-cancerous prostate cells (PNT1a). (B-C) Effect of hTERT gene knockdown using CrhTERT@ZIF-C on cancer cells. (B) hTERT mRNA fold expression of cancer cells treated with CrhTERT@ZIF-C by qPCR. Replicate data points shown. (C) Cell viability of PC-3, HeLa and MCF7 cells treated with ZIF-C loaded with CrhTERT for $24 \mathrm{~h}$ and $96 \mathrm{~h}$. For comparison, cells treated with ZIF-C served as vehicle control. Untreated cells were used as control. * ${ }^{*}<0.05$ compared with PNT1a cells and $24 \mathrm{~h}$ treatment. (D\&E) Effect of knockdown of hTERT on metastasis of cancer cells (D) Cell migration. A confluent layer of cells was scratched, treated with CrhTERT@ZIF-C and the distance of the scratch was measured at $0 \mathrm{~h}$ and $96 \mathrm{~h}$. Area of lesion covered is shown in percentage and presented in the bar graph. (E) Clonogenic cell survival assay of cells treated with CrhTERT@ZIF-C and allowed to grow for 14 days. Cells are stained with 1\% Crystal violet. Number of colonies were analyzed through ImageJ software and presented in bar graph. Cancer cells were treated with CrhTERT@ZIF-C for $3.5 \mathrm{~h}$ and allowed to grow for the intended time. Untreated cells were used as control. The results were shown as means \pm SD of triplicate experiments.

Subsequently, hTERT protein expression as a result of CrhTERT@ZIF-C mediated hTERT gene knockdown was measured in PC-3, HeLa and MCF7 cells. hTERT protein was detected using antibody staining by confocal microscopy (Figure 6A-C). Quantitative image analysis shown in Figure 6D in CrhTERT@ZIF-C treated PC-3, HeLa and MCF7 cells hTERT expression was decreased by ca.18\%, 29\%, and $26 \%$, respectively when compared to untreated cells. Thus, the hTERT knockdown mediated by CrhTERT@ZIF-C not only decrease the mRNA expression of hTERT but also decreased the protein expression of hTERT. 

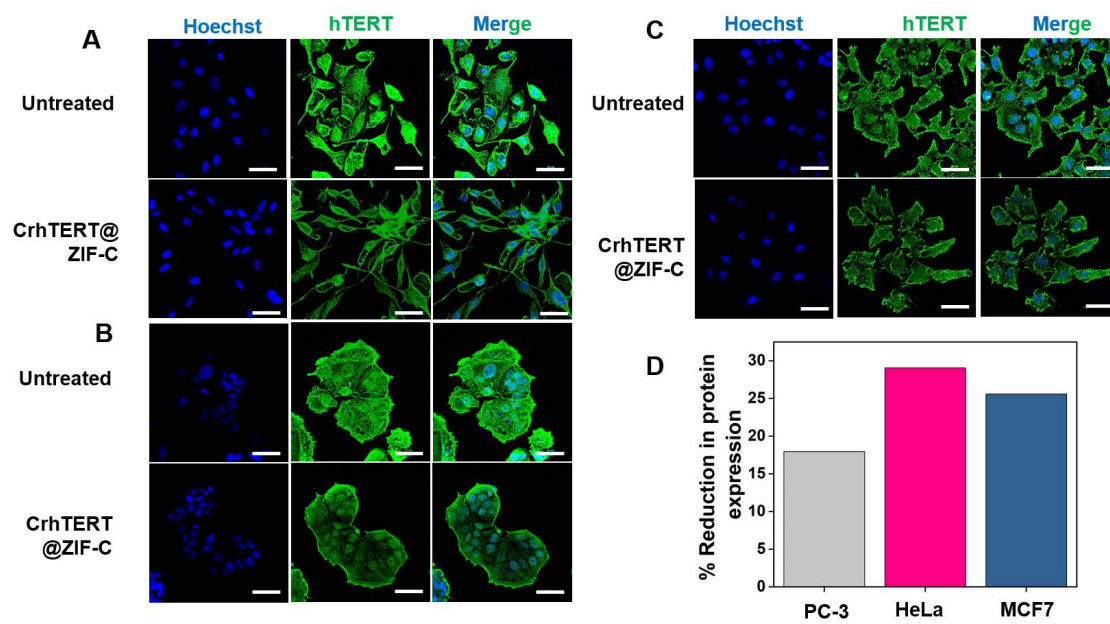

Figure 6. Expression of hTERT in cancer cells treated with CrhTERT@ZIF-C. Post transfection the cells were stained with hTERT antibody and the nuclei with Hoechst. Scale bar $50 \mu \mathrm{m}$. Untreated cells were used as control. (A) PC-3 cells (B) MCF7 cells (C) HeLa Cells (D) Percentage reduction in the hTERT expression was analyzed by ImageJ and represented in bar graph.

\section{Conclusion}

In general, CRISPR/Cas9 is valued as a powerful tool for gene knockdown and it holds much promise for cancer therapy. ${ }^{[42]}$ For the successful application of CRISPR/Cas9 systems for cancer, there is a need for targeting an oncogene that is universally expressed in cancer cells, but not in the normal cells. hTERT is one such gene that appears to express telomerase activity in $90 \%$ cancers but not in normal cells. Therefore, targeting hTERT has been proposed as a novel anticancer approach. In this study, hTERT was encapsulated in ZIF-C, a recently discovered non-porous MOF. When compared to the aqueous preparation of ZIF-8, ZIF-C possess a higher encapsulation efficiency (EE\% of ZIF-C is ca. $1.5 \mathrm{EE} \%$ of ZIF-8). Then, ZIF-C was able to protect the plasmid from DNase. Importantly, ZIF-C was able to deliver CRISPR/Cas9 plasmids into prostate, cervical and breast cancer cells in vitro, which further results in efficient genomic editing by knockdown of the hTERT gene. Therefore, ZIF-C can be a promising non-viral delivery system for therapeutic genes of large size $(9.2 \mathrm{kbp})$ in several cancer cell lines. We also found that hTERT gene edited cells have significantly enhanced cell apoptosis in vitro, suppressed cell proliferation, and cell migration. Thus, the results presented here demonstrate CrhTERT@ZIF-C as a generalized and promising CRISPR/Cas9-based delivery system for gene therapy. Further studies will focus on improving the transfection and gene editing efficiencies of ZIF-C employing strategies of surface modifications, before moving towards in vivo applications with an optimized and customizable non-viral gene therapy system.

((Note: Please place comprehensive details in the Supporting Information.))

\section{Acknowledgements}


S.P., A.P. and S.A.P are thankful to Australian Government for the RTP Stipend PhD scholarship support. R.S. acknowledges Ian Potter Foundation for the support in establishing Sir lan Potter NanoBiosensing Facility and ERASMUS K107 program for travel support to Falcaro Lab. RMIT Micro Nano Research (MNRF) and Microscopy \& Microanalysis (RMMF; a linked laboratory of the Microscopy Australia) facilities are acknowledged for access to equipment and technical assistance.

Keywords: Telomerase, CRISPR, ZIF, Cancer, hTERT

\section{References}

[1] J. Lindsey, N. I. McGill, L. A. Lindsey, D. K. Green, H. J. Cooke, Mutation Research/DNAging 1991, 256, 45-48.

[2] J. W. Shay, W. E. Wright, Nature Reviews Molecular Cell Biology 2000, 1, 72-76.

[3] aE. H. Blackburn, J. W. Szostak, Annual Review of Biochemistry 1984, 53, 163-194; bE. H. Blackburn, Nature 1991, 350, 569-573; cC. W. Greider, E. H. Blackburn, Cell 1987, 51, 887-898.

[4] D. Hanahan, R. A. Weinberg, Cell 2000, 100, 57-70.

[5] aL. K. Wai, MedGenMed 2004, 6, 19-19; bA. Bernal, L. Tusell, International Journal of Molecular Sciences 2018, 19.

[6] aN. W. Kim, M. A. Piatyszek, K. R. Prowse, C. B. Harley, M. D. West, P. L. Ho, G. M. Coviello, W. E. Wright, S. L. Weinrich, J. W. Shay, Science 1994, 266, 2011; bJ. W. Shay, S. Bacchetti, European Journal of Cancer 1997, 33, 787-791; cE. Hiyama, K. Hiyama, Cancer Letters 2003, 194, 221-233.

[7] aH. Zhu, M. Belcher, P. van der Harst, Clinical Science 2011, 120, 427-440; bM. Takakura, S. Kyo, T. Kanaya, H. Hirano, J. Takeda, M. Yutsudo, M. Inoue, Cancer Research 1999, 59, 551.

[8] aK. L. Kirkpatrick, K. Mokbel, European Journal of Surgical Oncology (EJSO) 2001, 27, 754-760; bE. Hiyama, K. Hiyama, T. Yokoyama, J. W. Shay, Neoplasia 2001, 3, 17-26; cW. C. Hahn, S. A. Stewart, M. W. Brooks, S. G. York, E. Eaton, A. Kurachi, R. L. Beijersbergen, J. H. M. Knoll, M. Meyerson, R. A. Weinberg, Nature Medicine 1999, 5, 1164-1170; dB. S. Herbert, A. E. Pitts, S. I. Baker, S. E. Hamilton, W. E. Wright, J. W. Shay, D. R. Corey, Proceedings of the National Academy of Sciences 1999, 96, 14276.

[9] C. Zhou, P. A. Gehrig, Y. E. Whang, J. F. Boggess, Molecular Cancer Therapeutics 2003, 2, 789.

[10] aM. Yaar, M. S. Eller, I. Panova, J. Kubera, L. H. Wee, K. H. Cowan, B. A. Gilchrest, Breast Cancer Research 2007, 9, R13; bH. Aoki, E. Iwado, M. S. Eller, Y. Kondo, K. Fujiwara, G.-Z. Li, K. R. Hess, D. R. Siwak, R. Sawaya, G. B. Mills, B. A. Gilchrest, S. Kondo, The FASEB Journal 2007, 21, 2918-2930; cR. T. Pitman, L. Wojdyla, N. Puri, Oncotarget; Vol 4, No 5: May 2013.

[11] aS. Horn, A. Figl, P. S. Rachakonda, C. Fischer, A. Sucker, A. Gast, S. Kadel, I. Moll, E. Nagore, K. Hemminki, D. Schadendorf, R. Kumar, Science 2013, 339, 959; bL. Stögbauer, W. Stummer, V. Senner, B. Brokinkel, Neurosurgical Review 2019.

[12] aC. Kailashiya, H. B. Sharma, J. Kailashiya, Vaccine 2017, 35, 5768-5775; bA. Kotsakis, E. K. Vetsika, S. Christou, D. Hatzidaki, N. Vardakis, D. Aggouraki, G. Konsolakis, V. Georgoulias, C. Christophyllakis, P. Cordopatis, K. Kosmatopoulos, D. Mavroudis, Annals of Oncology 2012, 23, 442-449.

[13] J. E. Garneau, M.-È. Dupuis, M. Villion, D. A. Romero, R. Barrangou, P. Boyaval, C. Fremaux, P. Horvath, A. H. Magadán, S. Moineau, Nature 2010, 468, 67-71.

[14] F. J. Sánchez-Rivera, T. Jacks, Nature Reviews Cancer 2015, 15, 387-393.

[15] D. Singh, S. H. Sternberg, J. Fei, J. A. Doudna, T. Ha, Nature Communications 2016, 7, 12778. 
[16] T. Gaj, S. J. Sirk, S.-L. Shui, J. Liu, Cold Spring Harb Perspect Biol 2016, 8, a023754.

[17] C. A. Lino, J. C. Harper, J. P. Carney, J. A. Timlin, Drug Delivery 2018, 25, 1234-1257.

[18] M. Hansen-Bruhn, B. E.-F. de Ávila, M. Beltrán-Gastélum, J. Zhao, D. E. Ramírez-Herrera, P. Angsantikul, K. Vesterager Gothelf, L. Zhang, J. Wang, Angewandte Chemie International Edition 2018, 57, $2657-2661$.

[19] aK. Lundstrom, Diseases 2018, 6; bW. Sun, W. Ji, J. M. Hall, Q. Hu, C. Wang, C. L. Beisel, Z. Gu, Angewandte Chemie International Edition 2015, 54, 12029-12033.

[20] H. Yue, X. Zhou, M. Cheng, D. Xing, Nanoscale 2018, 10, 1063-1071.

[21] R. Mout, M. Ray, G. Yesilbag Tonga, Y.-W. Lee, T. Tay, K. Sasaki, V. M. Rotello, ACS Nano 2017, 11, 24522458.

[22] M. Wang, J. A. Zuris, F. Meng, H. Rees, S. Sun, P. Deng, Y. Han, X. Gao, D. Pouli, Q. Wu, I. Georgakoudi, D. R. Liu, Q. Xu, Proceedings of the National Academy of Sciences 2016, 113, 2868.

[23] L. O. Alimi, M. Z. Alyami, S. Chand, W. Baslyman, N. M. Khashab, Chemical Science 2021, 12, $2329-2344$.

[24] M. d. J. Velásquez-Hernández, M. Linares-Moreau, E. Astria, F. Carraro, M. Z. Alyami, N. M. Khashab, C. J. Sumby, C. J. Doonan, P. Falcaro, Coordination Chemistry Reviews 2021, 429, 213651.

[25] S. K. Alsaiari, S. Patil, M. Alyami, K. O. Alamoudi, F. A. Aleisa, J. S. Merzaban, M. Li, N. M. Khashab, Journal of the American Chemical Society 2018, 140, 143-146.

[26] F. Carraro, M. d. J. Velásquez-Hernández, E. Astria, W. Liang, L. Twight, C. Parise, M. Ge, Z. Huang, R. Ricco, X. Zou, L. Villanova, C. O. Kappe, C. Doonan, P. Falcaro, Chemical Science 2020, 11, 3397-3404.

[27] A. Poddar, S. Pyreddy, F. Carraro, S. Dhakal, A. Rassell, M. R. Field, T. S. Reddy, P. Falcaro, C. M. Doherty, R. Shukla, Chemical Communications 2020, 56, 15406-15409.

[28] A. Poddar, J. J. Conesa, K. Liang, S. Dhakal, P. Reineck, G. Bryant, E. Pereiro, R. Ricco, H. Amenitsch, C. Doonan, X. Mulet, C. M. Doherty, P. Falcaro, R. Shukla, Small 2019, 15, 1902268.

[29] S. A. Basnayake, J. Su, X. Zou, K. J. Balkus, Inorganic Chemistry 2015, 54, 1816-1821.

[30] D. J. Quick, K. S. Anseth, Journal of Controlled Release 2004, 96, 341-351.

[31] E. Astria, M. Thonhofer, R. Ricco, W. Liang, A. Chemelli, A. Tarzia, K. Alt, C. E. Hagemeyer, J. Rattenberger, H. Schroettner, T. Wrodnigg, H. Amenitsch, D. M. Huang, C. J. Doonan, P. Falcaro, Materials Horizons 2019, 6, 969-977.

[32] D. Ibraheem, A. Elaissari, H. Fessi, International Journal of Pharmaceutics 2014, 459, 70-83.

[33] F. P. Seib, G. T. Jones, J. Rnjak-Kovacina, Y. Lin, D. L. Kaplan, Advanced Healthcare Materials 2013, 2, 1606-1611.

[34] M. A. Luzuriaga, C. E. Benjamin, M. W. Gaertner, H. Lee, F. C. Herbert, S. Mallick, J. J. Gassensmith, Supramolecular Chemistry 2019, 31, 485-490.

[35] S. Ramesan, A. R. Rezk, C. Dekiwadia, C. Cortez-Jugo, L. Y. Yeo, Nanoscale 2018, 10, 13165-13178.

[36] B. R. Liu, S.-Y. Lo, C.-C. Liu, C.-L. Chyan, Y.-W. Huang, R. S. Aronstam, H.-J. Lee, PLOS ONE 2013, 8, e67100.

[37] S. Mishra, J. D. Heidel, P. Webster, M. E. Davis, Journal of Controlled Release 2006, 116, $179-191$.

[38] S. A. Smith, L. I. Selby, A. P. R. Johnston, G. K. Such, Bioconjugate Chemistry 2019, 30, $263-272$.

[39] aA. L. Nagapoosanam, N. Ganesan, D. Umapathy, R. K. Moorthy, A. J. V. Arockiam, The Indian journal of medical research 2019, 149, 345-353; bP.-H. Zhang, L. Zou, Z.-G. Tu, Journal of Surgical Research 2006, 131, 143149. 
[40] T. S. Reddy, H. Kulhari, V. G. Reddy, V. Bansal, A. Kamal, R. Shukla, European Journal of Medicinal Chemistry 2015, 101, 790-805.

[41] H. Liu, Q. Liu, Y. Ge, Q. Zhao, X. Zheng, Y. Zhao, Scientific Reports 2016, 6, 22886.

[42] A. Fatima, H. Ikram ul, A. Zeeshan, K. Hamza, A. Muhammad Shrafat, Protein \& Peptide Letters 2020, 27, $1-14$. 
Supplementary information

ZIF-C as non-viral delivery system for CRISPR/Cas9 mediated hTERT knockdown in cancer cells.

Suneela Pyreddy, ${ }^{\mathrm{a}}$ Arpita Poddar, ${ }^{\mathrm{a}}$ Francesco Carraro, ${ }^{\mathrm{b}}$ Shakil Ahmed Polash, ${ }^{\mathrm{a}}$ Chaitali Dekiwadia, ${ }^{\mathrm{a}}$ Zeyad Nasa, ${ }^{\mathrm{a}}$

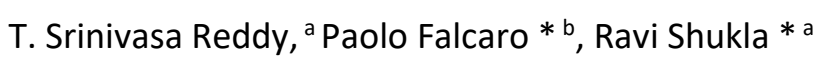

${ }^{a}$ Centre for Advanced Materials \& Industrial Chemistry, School of Science, RMIT University

Melbourne, Victoria 3001, Australia.

${ }^{\mathrm{b}}$ Institute of Physical and Theoretical Chemistry Graz University of Technology

Graz 8010, Austria.

Materials

Zinc acetate dehydrate, 2-Methylimidazole (2-mlm), ethylenediaminetetraacetic acid disodium salt dihydrate (EDTA), TBE (Tris-borate-EDTA) buffer, Chloroform, isopropanol, ethanol, Dimethyl sulfoxide (DMSO), chlorpromazine (CPZ), methyl- $\beta$-cyclodextrin $(M \beta C D)$, sodium azide $\left(\mathrm{NaN}_{3}\right)$, Amiloride, Luria-Bertani $(\mathrm{LB})$ broth and agarose were obtained from Sigma-Aldrich. GeneArt ${ }^{\circledR}$ CRISPR Nuclease Vector Kit, PureLink ${ }^{\mathrm{TM}}$ HiPure Plasmid Midiprep Kit, GeneArt genomic cleavage detection kit, YOYO ${ }^{\mathrm{TM}}-1$ lodide, TRIzol ${ }^{\mathrm{TM}}$ Reagent, High-Capacity cDNA Reverse Transcription Kit, Annexin V-FITC/PI staining assay kit, Hoechst 33342, Roswell Park Memorial Institute (RPMI) 1640 Medium, Fetal Bovine Serum (FBS), Penicillin-Streptomycin, TrypLE express, Lyso Tracker deep red and 3-(4,5-Dimethylthiazol-2-yl)-2,5-Diphenyltetrazolium Bromide (MTT) were obtained from ThermoFisher scientific. 


\section{Experimental Procedures}

\section{Construction of CRISPR/Cas9 plasmid with gRNA targeting hTERT (CrhTERT)}

The complementary oligonucleotide encoded for targeting hTERT (gRNA-FWD:

ACACATGCGTGAAACCTGAGAGGTTTT, gRNA- REV: CTCAGGTTTCACGCATGTGTCGGTG) are purchased from Invitrogen ('GeneArt CRISPR Search and Design Tool' True Design Genome Editor Software). These single-stranded oligonucleotides were annealed and ligated to the CRISPR plasmid vector which is purchased from Invitrogen (GeneArt ${ }^{\circ}$ CRISPR Nuclease Vector Kit). Once the doublestranded plasmid is constructed (CrhTERT), it is transformed into chemically competent E. coli DH $\alpha$ cells and amplified using LB plates containing $100 \mu \mathrm{g} / \mathrm{mL}$ ampicillin overnight at $37^{\circ} \mathrm{C}$ incubator. Successful grown 3-5 colonies were picked and amplified in LB broth containing $100 \mu \mathrm{g} / \mathrm{mL}$ separately overnight at $37^{\circ} \mathrm{C}$ incubator at $200 \mathrm{rpm}$. Later, the plasmid was isolated using PureLink ${ }^{\mathrm{TM}}$ HiPure Plasmid Midiprep Kit. Finally, CrhTERT was dissolved in nuclease-free water and quantified by Nanodrop spectrophotometer at absorbance $260 / 280 \mathrm{~nm}$. Later, CrhTERT plasmid is stored at $-20^{\circ} \mathrm{C}$ for further use. The details of chemically competent $E$. coli cell preparation and transformation of plasmid are provided in supporting information.

\section{Preparation of chemically competent Escherichia coli DH5a cells.}

Pick a single colony of E. coli DH5 $\alpha$ from a fresh culture plate and inoculated in $5 \mathrm{~mL}$ of Super Optimal Broth (SOB) medium. Later, it was incubated overnight at $37^{\circ} \mathrm{C}(220-280 \mathrm{rpm})$. After incubation, $1 \mathrm{~mL}$ of overnight inoculum was incubated in $100 \mathrm{~mL}$ of SOB medium at $25-30^{\circ} \mathrm{C}(220-$ $280 \mathrm{rpm}$ ) until the culture achieves OD600 0.6. At this point, the flask was transferred onto the ice for $10 \mathrm{~min}$ to stop further multiplication. Later, the chilled culture was poured into an ice-cold sterile tube and centrifuge at $2500 \mathrm{rcf} 10 \mathrm{~min}$ at $4^{\circ} \mathrm{C}$. To the pellet $40 \mathrm{~mL}$ of chilled transformation buffer ( $55 \mathrm{mM} \mathrm{MnCl} \cdot 4 \mathrm{H} 2 \mathrm{O}, 15 \mathrm{mM} \mathrm{CaCl} 2 \cdot 2 \mathrm{H} 2 \mathrm{O}, 250 \mathrm{mM} \mathrm{KCl}, 10 \mathrm{mM}$ piperazine- $\mathrm{N}, \mathrm{N}^{\prime}$-bis(2-ethanesulfonic acid) (PIPES) (0.5M, pH 6.7)) was added and incubated for 15 min which was followed by centrifugation at $2500 \mathrm{rcf}$ for $10 \mathrm{~min}$ at $4^{\circ} \mathrm{C}$. The cell pellet was resuspended in $5 \mathrm{~mL}$ of ice-cold transformation buffer and incubate on ice for $5 \mathrm{~min}$. Later $187 \mu \mathrm{L}$ of DMSO was added, gently mixed and placed on ice for $5 \mathrm{~min}$. Aliquot $100 \mu \mathrm{L}$ of competent cells was poured into ice-cold tubes and quickly freeze the tube in liquid nitrogen and store them at $-80^{\circ} \mathrm{C}$.

\section{Transformation of plasmid to competent cells.}

The aliquot of chemically competent cells was thawed on ice and mix the cells with 3-5 $\mu \mathrm{L}$ of plasmid by flicking the tube with a finger. Heat shook the cells by placing the tube in $42^{\circ} \mathrm{C}$ water bath for 50 seconds, then the tube was placed on ice for 2 min. Later, $900 \mu \mathrm{L}$ of SOC medium (SOB medium with 
$20 \mathrm{mM}$ glucose) was added and incubated with shaking at $37^{\circ} \mathrm{C}$ for $30-60 \mathrm{~min}$. Finally, transformed culture was spread on the LB agar plate contain $100 \mu \mathrm{g} / \mathrm{mL}$ ampicillin and incubated at $37^{\circ} \mathrm{C}$ overnight for the colony growth.

The structure of CrhTERT plasmid

The successfully ligated plasmid contains the following regions

1. crRNA - guide RNA (gRNA) sequence coded for target gene hTERT.

2. tracrRNA - Auxiliary trans-activating crRNA allows loading of Cas9 nuclease onto the gRNA.

3. OFP - Reporter gene for orange fluorescent protein.

4. Pol III terminator - Allows termination of RNA Polymerase III-dependent transcription.

5. pUC origin - Permits high-copy replication and maintenance in E. coli.

6. Ampicillin resistance gene - Allows selection of the plasmid in E. coli.

7. $\mathrm{CMV}$ promoter ( $\left.\mathrm{P}_{\mathrm{CMV}}\right)$ - Allows expression of Cas9 nuclease and OFP reporter genes.

8. Cas9 - Cas9 nuclease coding sequence.

9. 2A peptide linker - A self-cleaving peptide linker connecting OFP reporter genes to the Cterminal end of Cas9 nuclease.

10. TK pA - Polyadenylation signal.

11. F1 origin of replication - Origin of replication.

12. Human U6 promoter - Allows RNA Polymerase III-dependent expression of the gRNA.

\section{Synthesis of CrhTERT@ZIF-C}

CrhTERT ( $3 \mu \mathrm{g}$ ) was added to $100 \mu \mathrm{L}$ aqueous solution of $2-\mathrm{mlm}(160 \mathrm{mM})$ followed by addition of a $100 \mu \mathrm{L}$ of zinc acetate dihydrate solution $(40 \mathrm{mM})$, the solution immediately changes from clear to cloudy. The solution was incubated at room temperature for $10 \mathrm{~min}$. Later, resulting CrhTERT@ZIF-C product was collected and washed with water thrice by centrifuging at $10000 \mathrm{rcf}$ for $10 \mathrm{~min}$ to remove unreacted precursors. ${ }^{1}$

\section{Synthesis of CrhTERT@ZIF-8}


CrhTERT $(3 \mu \mathrm{g})$ was added to $100 \mu \mathrm{L}$ aqueous solution of $2-\mathrm{mIm}(2560 \mathrm{mM})$ followed by addition of a $100 \mu \mathrm{L}$ of zinc acetate dihydrate solution $(40 \mathrm{mM})$, the solution immediately changes from clear to cloudy. The solution was incubated at room temperature for $10 \mathrm{~min}$. Later, the resulting CrhTERT@ZIF-C product was collected and washed with water thrice by centrifuging at 10000 rcf for 10 min to remove unreacted precursors.

\section{Synthesis of ZIF-C}

$240 \mu \mathrm{L}$ of a $440 \mathrm{mM}$ aqueous solution of $2-\mathrm{mIm}$ and $1380 \mu \mathrm{L}$ of deionized water were mixed in a $2 \mathrm{ml}$ plastic centrifuge tube for 1 minute. Then, $380 \mu \mathrm{L}$ of $80 \mathrm{mM}$ aqueous solution of $\mathrm{Zn}(\mathrm{OAc})_{2} \cdot 2\left(\mathrm{H}_{2} \mathrm{O}\right)$ was added to the mixture. The reaction mixture was left under static conditions at RT for $24 \mathrm{~h}$. After this reaction time, the material was collected and washed with water thrice by centrifuging at 10000 rcf for $10 \mathrm{~min}$ to remove unreacted precursors.

\section{Scanning electron microscopy (SEM)}

Carl Zeiss Gemini Field Emission Scanning Electron Microscope (FESEM) was used to investigate the particle morphology. CrhTERT@ZIF-C ( $2 \mu \mathrm{L})$ was drop-cast on a silicon wafer, air-dried and sputter coated with iridium. The instrument is operated at accelerating voltage of $5.0 \mathrm{kV}$ with High Efficiency (HE-SE2) detector for collecting secondary electrons was used to take images.

\section{Transmission electron microscopy (TEM)}

TEM images were observed using JOEL 1010 TEM instrument. The sample was prepared by drop coating the synthesized CrhTERT@ZIF-C on a strong carbon TEM grid. Images were collected using accelerating voltage of $80 \mathrm{kV}$.

\section{Powder X-ray diffraction (PXRD)}

Prior to analysis, the dry powders of the samples were dispersed in deionized water $(50 \mu \mathrm{l})$ with a micropipette and drop-cast on $15 \mathrm{~mm}^{2}$ Silicon (100) wafers. The drop-casts were dried overnight at room temperature and pressure. The XRD patterns were acquired using a Rigaku SmartLab equipped with a $9 \mathrm{~kW}$ rotating $\mathrm{Cu}$ anode.

\section{Fourier-transform infrared spectroscopy (FTIR)}

The synthesized biocomposites were analyzed using Perkin Elmer Spectrum 100 instrument. Potassium bromide $(\mathrm{KBr})$ was added to the synthesized biocomposites. This mixture was incubated at $60-70^{\circ} \mathrm{C}$ for $1 \mathrm{~h}$ to get rid of moisture. Then the mixture was transferred to the sample holder. Data was collected from $4000-400 \mathrm{~cm}-1$ for 128 scans with $4 \mathrm{~cm}-1$ resolution. 


\section{Analysis of loading efficiency}

The loading efficiency of ZIF-C and ZIF-8 was examined and quantified by agarose gel electrophoresis. In agarose gel electrophoresis, the loading efficiency of CrhTERT@ZIF-C and CrhTERT@ZIF-8 was determined by analysing the electrophoretic mobility of the plasmid on the agarose gel. After incubation time, biocomposites are centrifuged for $10 \mathrm{~min}$ at $10000 \mathrm{rcf}$ and supernatant was collected to determine the unloaded plasmid. Biocomposites were digested with EDTA $(20 \mathrm{mM})$ to obtain the total amount of plasmid loaded. ${ }^{2}$ The samples were loaded on $1 \%$ agarose gel containing SYBR Safe against pure plasmid as control. Electrophoresis was carried out for 60 min at $90 \mathrm{~V}$ in 1 X TBE buffer and bands were visualized in GelDoc ${ }^{\circ}$ (BioRad ${ }^{\circ}$, USA)

In addition, loading efficiency by fluorescence spectroscopy was also determined using Invitrogen ${ }^{\mathrm{TM}}$ Quant-iT ${ }^{\mathrm{TM}}$ PicoGreen ${ }^{\mathrm{TM}}$ dsDNA Assay Kit. The supernatant, EDTA treated CrhTERT@ZIF-C and pure plasmid were incubated with a solution of PicoGreen dye according to the manufacture's protocol for 2 to $5 \mathrm{~min}$ at room temperature protected from light. Later, the samples were analyzed by fluorescence spectroscopy at emission intensity of $528 \mathrm{~nm}$.

\section{Protection Assay}

Protection assay was performed using TURBO ${ }^{\text {TM }}$ DNase (Invitrogen) following manufacturer's protocol.CrhTERT@ZIF-C, ZIF-C incubated with CrhTERT and CrhTERT were added with DNase I (1 $\mu \mathrm{L}$ of $2 \mathrm{U} / \mu \mathrm{L}$ ) and incubated for 30 mins at $37^{\circ} \mathrm{C}$. Post incubation, inactivation reagent was added to all the sample to inactivate DNase I followed by centrifugation for $10 \mathrm{mins}$ at $10000 \mathrm{rcf}$. The pellet is resuspended in $10 \mu \mathrm{L}$ of aqueous solution. 20mM EDTA was added to CrhTERT@ZIF-C to digest the ZIFC, followed by loading the samples in 1\% agarose gel electrophoresis using untreated CrhTERT@ZIFC. Electrophoresis was carried out for $60 \mathrm{~min}$ with $90 \mathrm{~V}$ in 1 X TBE buffer and bands were visualized in GelDoc ${ }^{\circ}$ (BioRad ${ }^{\circ}$, USA).

\section{Standard curve for determination of plasmid concentration.}

The CrhTERT plasmid concentration was quantified by Quant-iT ${ }^{\text {TM }}$ PicoGreen ${ }^{\text {TM }}$ dsDNA Assay Kit by taking different concentrations of the plasmid $(0.1,1,10,50,100 \mathrm{ng} / \mathrm{mL})$ and then fluorescence intensity was detected using SpectraMax Paradigm Multi-mode Microplate Reader.

\section{Cell Culture}

PC-3, MCF7 and HeLa cells were provided by Olivia Newton-John Cancer Research Centre. PC-3 and HeLa cells were cultured in culture flask using Roswell Park Memorial Institute (RPMI) 1640 medium supplemented with $10 \%$ fetal bovine serum and $100 \mathrm{IU} / \mathrm{mL}$ penicillin-streptomycin. MCF7 cells were 
cultured in culture flask containing Dulbecco's Modified Eagle Medium (DMEM) supplemented with $10 \%$ fetal bovine serum and $100 \mathrm{IU} / \mathrm{mL}$ penicillin-streptomycin and incubated in humidified $5 \% \mathrm{CO}_{2}$ at $37^{\circ} \mathrm{C}$ incubators. After achieving confluence $(>80 \%)$, cells were trypsinized with TrypLE express solution for 3-5 mins and seeded in culture flask at a seeding density of $5.0 \times 10^{3}$ cells $/ \mathrm{cm}^{2}$.

\section{Cell Transfection}

Cells $\left(0.35 \times 10^{6}\right.$ cells/well) were seeded in 6 -well plate with $2 \mathrm{~mL}$ of RPMI medium and allowed to reach $\sim 80 \%$ confluency. Later, $2 \mathrm{~mL}$ of fresh RPMI/DMEM media is replaced with the culture media. CrhTERT@ZIF-C (containing $3 \mu \mathrm{g}$ of plasmid) incubated in $200 \mu \mathrm{L}$ Opti-MEM was added dropwise to the wells and incubated at $37^{\circ} \mathrm{C}$ with $5 \% \mathrm{CO}_{2}$ for $3.5 \mathrm{~h}$. Then, the supernatant was replaced by fresh RPMI medium and observed for transfection. Images of transfected cells were acquired with Bio-Rad $\mathrm{ZOE}^{\mathrm{TM}}$ fluorescence microscope and quantified by BD-Accuri C6 flow cytometry.

\section{Cellular internalization studies}

For fluorescence imaging, plasmid CrhTERT ( $3 \mu \mathrm{g})$ was mixed with YOYO-1 solution $(0.1 \mu \mathrm{M})$ in the ratio of 1 YOYO-1 dye molecule to 20 base pairs of DNA and incubated for $30 \mathrm{~min}$ at $37^{\circ} \mathrm{C}$ to obtain YOYO- labelled plasmid (Y-CrhTERT). Later, Y-CrhTERT@ZIF-C were synthesized using the Y-CrhTERT. Cells were seeded in a 6 -well plate $\left(0.35 \times 10^{6}\right.$ cells/well) and incubated at $37^{\circ} \mathrm{C}$ for $24 \mathrm{~h}$. Later, the culture medium was removed and $2 \mathrm{~mL}$ of fresh medium containing Y-CrhTERT@ZIF-C (1.5 $\mu \mathrm{g} / \mathrm{mL})$ was added to the cells and incubated at $37^{\circ} \mathrm{C}$. After each time interval $(1,3,6$ and $24 \mathrm{~h})$ the cells were carefully washed with PBS thrice to remove Y-CrhTERT@ZIF-C that are not internalized by the cells and fixed with $4 \%$ paraformaldehyde. Finally, the cell nuclei were stained with Hoechst 33342, the cells were imaged by Bio-Rad ZOE ${ }^{\mathrm{TM}}$ fluorescent microscope.

Further quantification of cellular uptake was determined by flow cytometry. After cells were treated with Y-CrhTERT@ZIF-C as the same procedure mentioned above, the cells were trypsinized and collected by centrifugation at $1000 \mathrm{rpm}$ for $5 \mathrm{~min}$. Then washed thrice with PBS and re-suspended in PBS and examined by BD-Accuri C6 flow cytometer.

\section{Scanning Electron Microscopy (SEM)}

For SEM imaging, cells allowed to grow for overnight on coverslips. Post treatment the cells were washed thrice with PBS and fixed immediately with $4 \%$ glutaraldehyde for $15 \mathrm{~min}$ at room temperature. After which they are washed thrice with $0.1 \mathrm{M}$ sodium cacodylate buffer. Followed by the dehydration in graded series of ethanol from $50 \%$ to $100 \%$ ethanol for $10 \mathrm{~min}$. For the final step $100 \%$ ethanol was added for $30 \mathrm{~min}$ and removed. The samples were dried at room temperature for 
an hour. Finally, the coverslips were carbon coated with Leica Sputter coater. High resolution images were obtained with FEI Verios 460L SEM under high vacuum conditions.

\section{Transmission Electron Microscopy (TEM)}

For TEM, post treatment cells were primary fixed with $2 \%$ glutaraldehyde and $2.5 \%$ paraformaldehyde in $0.1 \mathrm{M}$ sodium cacodylate buffer. Further they were fixed with $1 \%$ osmium tetroxide for $2 \mathrm{~h}$ at room temperature, followed by washing with $0.1 \mathrm{M}$ sodium cacodylate buffer thrice by centrifugation at $1000 \mathrm{rpm}$ for $5 \mathrm{~min}$. The samples were dehydrated with $50 \%, 70 \%, 90 \%$ and $100 \%$ ethanol for 15 min each step. Cells were completely dehydrated with $100 \%$ acetone for 30 min twice after which they are infiltrated twice with equal parts of acetone and Spur's resin. They were further infiltrated twice with $100 \%$ resin under vacuum. The resin containing samples was cured at $70^{\circ} \mathrm{C}$ for $48 \mathrm{~h}$. For imaging ultrathin section of the cells was sectioned, post stained and imaged under JEOL 1010 TEM at $100 \mathrm{kV}$.

To study the mechanism of cellular uptake, the cells were pretreated with different endocytosis inhibitors $(10 \mu \mathrm{g} / \mathrm{mL}$ of chlorpromazine (CPZ) for inhibition of clathrin-mediated endocytosis, $5 \mathrm{mM}$ of methyl- $\beta$-cyclodextrin $(\mathrm{M} \beta \mathrm{CD}$ ) for caveolin-mediated endocytosis, $75 \mu \mathrm{g} / \mathrm{mL}$ of amiloride for macropinocytosis and $3 \mathrm{mg} / \mathrm{mL}$ of sodium azide (NaN3) for inhibition of ATP) at $37^{\circ} \mathrm{C}$ or incubated at $4^{\circ} \mathrm{C}$ for $0.5 \mathrm{~h}$. Later, the cells were co-treated with Y-CrhTERT@ZIF-C for $6 \mathrm{~h}$, then cells were harvested and analyzed by BD-Accuri C6 flow cytometry.

To further investigate the cellular internalization at subcellular level, PC-3 cells were treated with CrhTERT@ZIF-C for $3 \mathrm{~h}$ and $6 \mathrm{~h}$. After incubation lysotracker, deep red was added to the cells and incubated for 40 mins. Later cells were washed thrice with PBS and counterstained with Hoechst 33342 stain to stain the nucleus and analyzed by N- STORM SuperResolution/Confocal microscope, Nikon.

\section{Genome cleavage detection assay}

GeneArt genomic cleavage detection kit was used to detect the genomic editing. Post transfection, the genomic DNA is extracted from the harvested cells treated with CrhTERT@ZIF-C by protein degrader and a cell lysate using the thermo cycle run at $68^{\circ} \mathrm{C} 15 \mathrm{~min}, 95^{\circ} \mathrm{C} 10 \mathrm{~min}$ and $4^{\circ} \mathrm{C}$ hold. According to manufacturer's instructions, the Loci where they are amplified by PCR using primers: hTERT GCD forward primer 5'-CCACCATGGGGCAAACAGGA-3', GCD reverse primer 5'ACAGACACGCAGCTACTCGCA-3' at reaction rate of $\left(95^{\circ} \mathrm{C}\right)$ for 10 minutes, $\left(95^{\circ} \mathrm{C}\right.$ for $30 \mathrm{~s} ; 55^{\circ} \mathrm{C}$ for $30 \mathrm{~s}, 72^{\circ} \mathrm{C}$ for $\left.30 \mathrm{~s}\right)$ for 40 cycles and $\left(72{ }^{\circ} \mathrm{C}\right.$ for 7 minutes) one cycle. The amplicons were subsequently used for the cleavage assay by setting up a denaturing and re-annealing reaction 
resulting in the heterogeneous DNA duplexes at reaction conditions of $95^{\circ} \mathrm{C} 5 \mathrm{~min}, 95^{\circ} \mathrm{C}-85^{\circ} \mathrm{C}$ [ramp rate $\left.-2^{\circ} \mathrm{C} / \mathrm{sec}\right], 85^{\circ} \mathrm{C}-25^{\circ} \mathrm{C}$ [ramp rate $-0.1^{\circ} \mathrm{C} / \mathrm{sec}$ ] and $4^{\circ} \mathrm{C}$-hold. Immediately the heteroduplex DNA is cleaved by the detection enzyme by incubating the sample with detection enzyme for $1 \mathrm{~h}$ at $37^{\circ} \mathrm{C}$ and the samples were analyzed by $2 \%$ agarose gel electrophoresis for cleavage and indel formation efficiencies were calculated using ImageJ.

\section{Gene expression studies}

\section{RNA Extraction}

Cells $(2.5 \times 105$ cells/well) were plated in 6 -well plates and incubated for $24 \mathrm{~h}$. After $24 \mathrm{~h}$ incubation time, total RNA was extracted using TRIzol reagent. Cell lysis was performed by incubating the cells with $1 \mathrm{~mL}$ Trizol for $5 \mathrm{~min}$ on ice, samples transferred to $1.5 \mathrm{~mL}$ Eppendorf centrifuge tubes and 0.2 $\mathrm{mL}$ of chloroform added. Tubes were then inverted 10 times followed by centrifugation at 12000 rpm for $15 \mathrm{~min}$ at $4^{\circ} \mathrm{C}$. The aqueous phase was carefully withdrawn and transferred to new $1.5 \mathrm{~mL}$ Eppendorf tubes. $0.25 \mathrm{~mL}$ of isopropanol was added to the aqueous phase and invert 10 times, allow to room temperature for 10 mins for RNA precipitation. Samples were centrifuged at $12000 \mathrm{rpm}$ for $15 \mathrm{~min}$ at $4^{\circ} \mathrm{C}$. The supernatant was removed, and the resulting pellet was washed with $1.0 \mathrm{~mL}$ of $75 \%$ ethanol. Samples were then centrifuged at $12000 \mathrm{rpm}$ for $15 \mathrm{~min}$ at $4^{\circ} \mathrm{C}$, the supernatant was discarded, and the pellet was air-dried for 5 min then resuspended in $10 \mu \mathrm{L}$ of DNase, RNase free water. RNA was stored at $-80^{\circ} \mathrm{C}$. RNA concentration was determined with a Nanodrop (Thermo Scientific, USA).

\section{cDNA Conversion}

cDNA conversion was carried out by taking $2 \mu \mathrm{g}$ of RNA in $10 \mathrm{~mL}$ nuclease-free water, $2 \mathrm{~mL}$ of 10X RT buffer, $0.8 \mathrm{~mL}$ of $25 \mathrm{X}$ dNTP mix $(100 \mathrm{mM}), 2 \mathrm{~mL}$ of $10 \mathrm{X}$ random primers and $3.2 \mu \mathrm{L}$ of nuclease-free water with a total of $20 \mu \mathrm{l}$ of the reaction mixture. Then the reaction mixture is placed in thermal PCR under cycle condition of $25^{\circ} \mathrm{C}$ for $10 \mathrm{~min}, 37^{\circ} \mathrm{C}$ for $2 \mathrm{~h}$, and $85^{\circ} \mathrm{C}$ for $5 \mathrm{~min}$ and finally hold at $4^{\circ} \mathrm{C}$. The resulting cDNA was stored at $-20^{\circ} \mathrm{C}$. qPCR was carried out in $10 \mu \mathrm{L}$ containing TaqMan ${ }^{\text {TM }}$ Fast Universal PCR Master Mix (2X), no AmpErase ${ }^{\mathrm{TM}}$ UNG (ThermoFisher) and $0.5 \mu \mathrm{L}$ (300 nM) of TaqMan $^{\text {TM }}$ Gene Expression Assay (FAM) ID Hs01566408_m1 (for target TERT) and Hs02786624_g1 (for housekeeping gene GAPDH) and $2 \mu \mathrm{L}$ of cDNA. The fold change in mRNA expression was determined by fold-over untreated method.

\section{Cell proliferation assay}

Cells were seeded in 96 well plates with RPMI media (100 $\mu \mathrm{L} /$ well; 10000, and 2500 cells/ well for 24 $\mathrm{h}$ and $96 \mathrm{~h}$ respectively) and incubated at $37^{\circ} \mathrm{C}$ for $24 \mathrm{~h}$. Later, cells were treated with $100 \mu \mathrm{L}$ RPMI 
medium containing CrhTERT@ZIF-C and ZIF-C followed by incubation for $3.5 \mathrm{~h}$ at $37^{\circ} \mathrm{C}$. The medium was replaced with $100 \mu \mathrm{L}$ of fresh RPMI medium. Later, at respective time point media was aspirated in the plate and $100 \mu \mathrm{L}$ of serum-free RPMI medium containing $0.5 \mathrm{mg} / \mathrm{mL}$ of MTT was added and incubated at $37^{\circ} \mathrm{C}$ for $4 \mathrm{~h}$ in dark. After incubation, medium containing MTT was aspirated carefully without disturbing purple formazan crystals. The purple formazan crystals were dissolved in DMSO and the absorbance was measured by microplate reader at $570 \mathrm{~nm}$ with the reference wavelength of $630 \mathrm{~nm}$. The percentage cell viability is calculated by formula [(absorbance of treated cells/ absorbance of untreated cells) *100].

\section{Clonogenic assay}

For the clonogenic assay, cells were seeded onto 6-well plate at the seeding density of 1000 cells/well and incubated for $24 \mathrm{~h}$ at $37^{\circ} \mathrm{C}$. Then cells were treated with CrhTERT@ZIF-C for $3.5 \mathrm{~h}$ at $37^{\circ} \mathrm{C}$ and replaced media with fresh media. Cells were maintained for 14 days in complete medium for colonies appearance. The colonies were fixed with $4 \%$ paraformaldehyde and stained with $1 \%$ crystal violet. The plates were scanned using Epson Perfection V700 Photo scanner and quantified by ImageJ software.

\section{In vitro cell migration assay}

Cells were cultured in 6 -well plate $\left(5 \times 10^{5}\right.$ cells/well) upon $90 \%$ confluency, cells were treated with CrhTERT@ZIF-C for 3.5 h. A scratch wound was made by using a $200 \mu \mathrm{L}$ pipette tip in the monolayer culture. The migration of the cells was photographed for time intervals under phase-contrast microscopy and the images were quantified using ImageJ software.

\section{hTERT protein expression}

Post transfection, the cells were fixed in $4 \%$ paraformaldehyde and washed with PBS ( $x 3$ ). For staining, PBS is removed, and cells were permeabilized with $0.02 \%$ Triton X-100 in PBS for 20 min followed by blocking with $2 \%$ bovine serum albumin (BSA) in PBS for $30 \mathrm{~min}$. Cells were treated with 1:200 dilution of mouse anti TERT monoclonal antibody in blocking buffer for $1 \mathrm{~h}$. After washing with PBS (x3), cells were incubated with 1:500 of goat anti-mouse secondary antibody tagged with Alexa Fluor $^{\circledR} 594$ in blocking buffer for 30 min in dark. After incubation, cells were washed with PBS (x3) and finally stained the nuclei with Hoechst 33342. Finally, they were analyzed using BD-C6 accuri flow-cytometer and imaged by using N- STORM SuperResolution/Confocal microscope, Nikon. 


\section{hTERT oligonucleotide}

T3-FWD Sequence: ACACATGCGTGAAACCTGAGAGGTTTT

T3-REV Sequence: CTCAGGTTTCACGCATGTGTCGGTG

Step 1: Annealed and cloned to CRISPR

nuclease vector

A

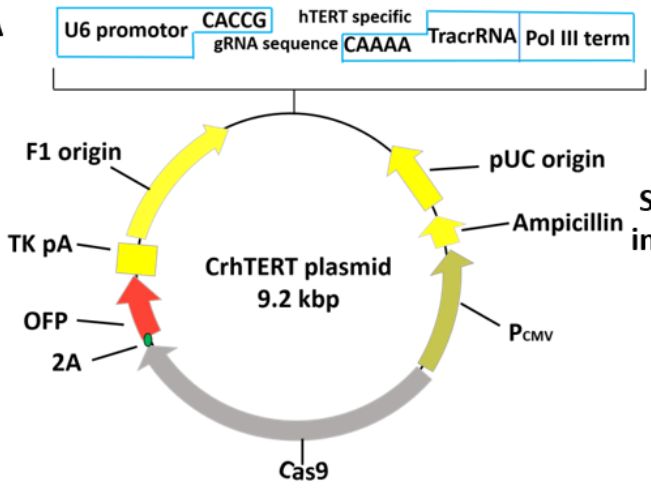

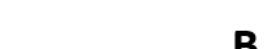

B

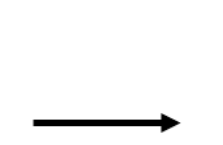

Step 2: Transformed into competent E.coli DH5 $\alpha$ cells

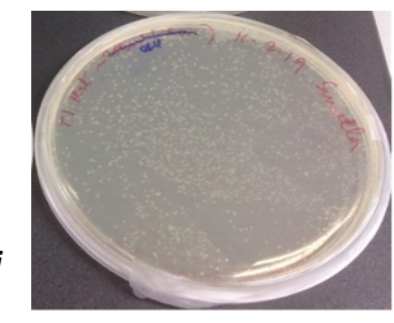

Step 3: Plasmid is isolated and sequenced to confirm the construct

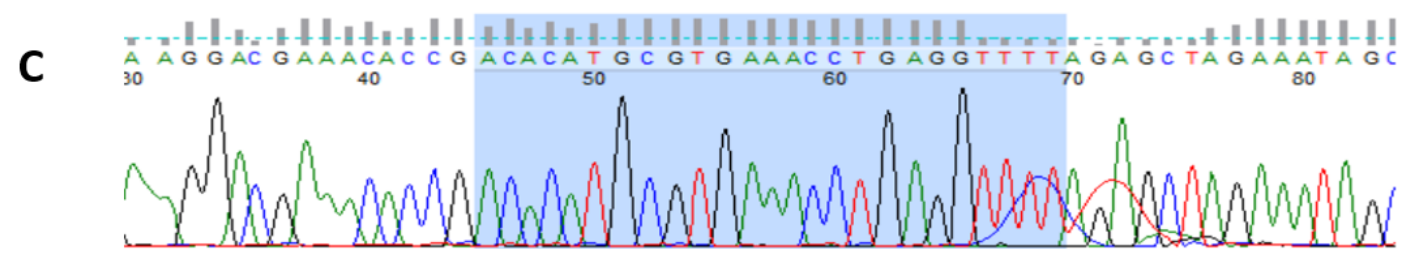

Figure S1. Construction of CrhTERT plasmid. (A) A Schematic diagram of CRISPR nuclease vector containing regions encoded for Cas9 protein, Orange fluorescence protein (OFP) and Ampicillin resistance gene. (B) Competent E. coli DH5 $\alpha$ cells were transformed with CrhTERT plasmid on LB agar plate with $100 \mu \mathrm{g} / \mathrm{mL}$ ampicillin. (C) The partial Sanger sequencing chromatogram of CrhTERT plasmid with highlighted gRNA sequence. 


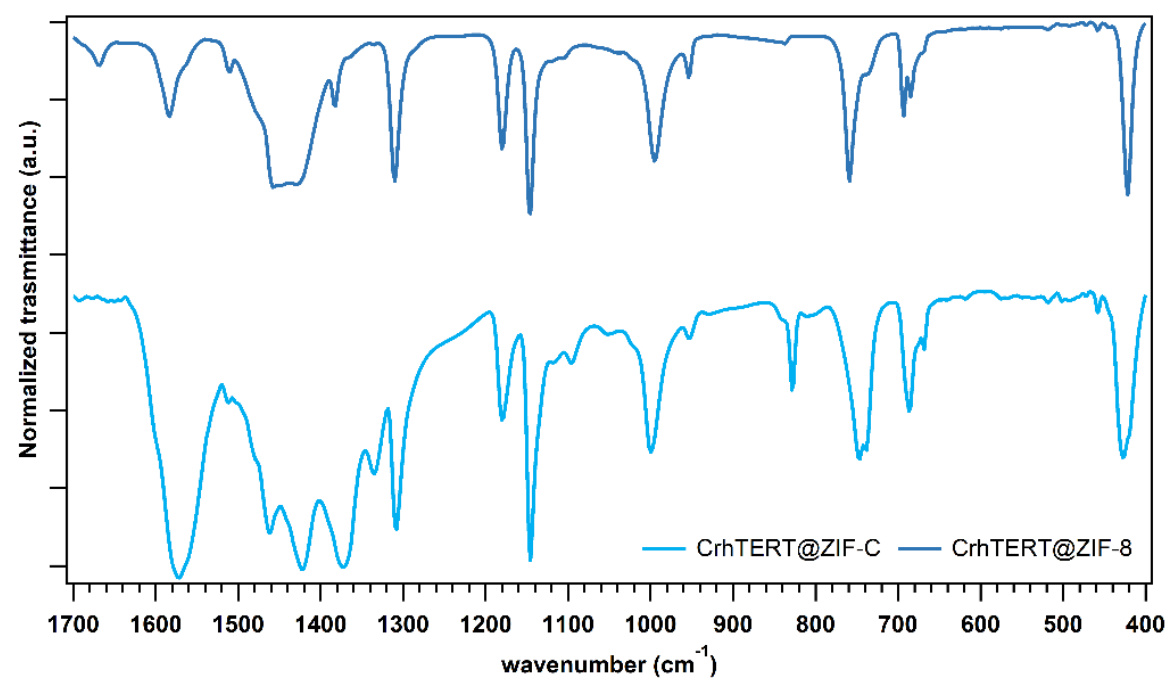

Figure S2. Fourier transform infrared spectra of CrhTERT@ZIF-C and CrhTERT@ZIF-8.

The supernatant of CrhTERT@ZIF-C and CrhTERT@ZIF-8 shows the faint plasmid bands in the lane with c.a. $12 \%$ and $28 \%$ intensity match, respectively for ZIF-C and ZIF-8, indicating the percentage of plasmid remained unloaded in the supernatants.

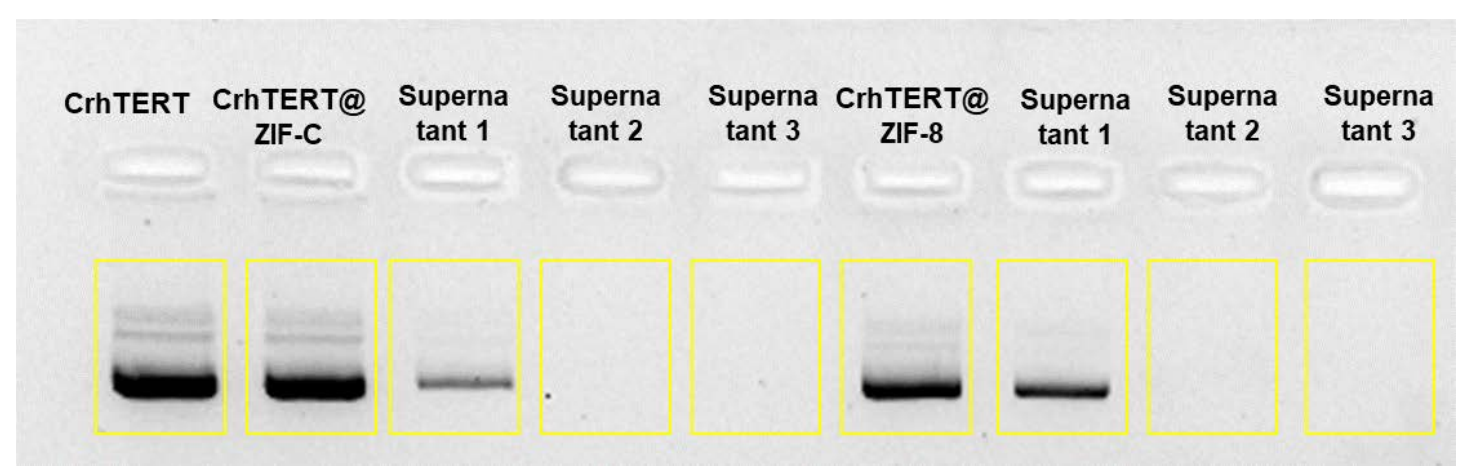

Figure S3. Loading efficiency by Agarose gel electrophoresis of CrhTERT@ZIF-C and CrhTERT@ZIF-8.

Loading efficiency of CrhTERT@ZIF-C was also assessed through fluorescence spectroscopy using Quant-iT $\mathrm{T}^{\mathrm{TM}}$ PicoGreen reagent. PicoGreen binds with DNA to give fluorescence at $\lambda \max 528 \mathrm{~nm}$. Post synthesis, EDTA treated CrhTERT@ZIF-C, supernatant, and control CrhTERT were incubated with Pico Green reagent. As can be seen in Figure S4, the characteristic peak at $\lambda \max 528 \mathrm{~nm}$ is present in the dissolved pellet CrhTERT@ZIF-C with similar intensity to that of control plasmid. The peak is absent in the supernatant; further indicating plasmid loading with the ZIF-C particles. 


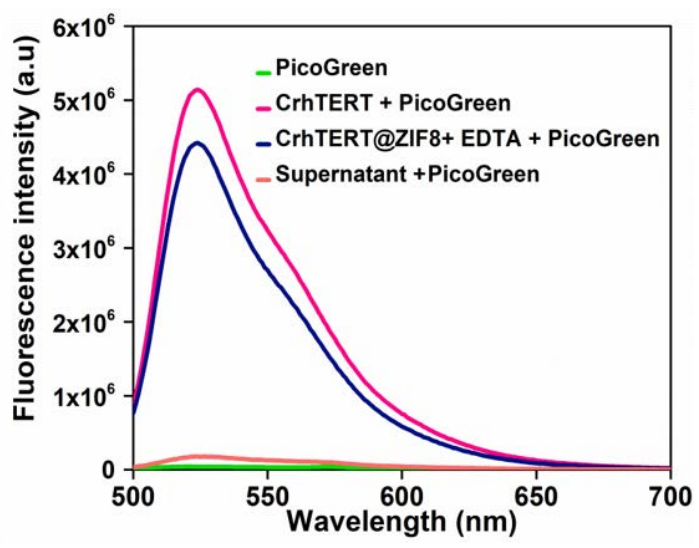

Figure S4. Loading efficiency by fluorescence emission spectra of CrhTERT plasmid, EDTA digested CrhTERT@ZIF-C, Supernatant along with PicoGreen dye and Just PicoGreen dye at $528 \mathrm{~nm}$.

A

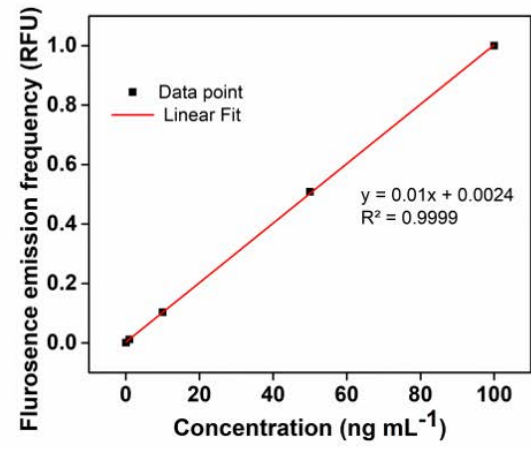

B

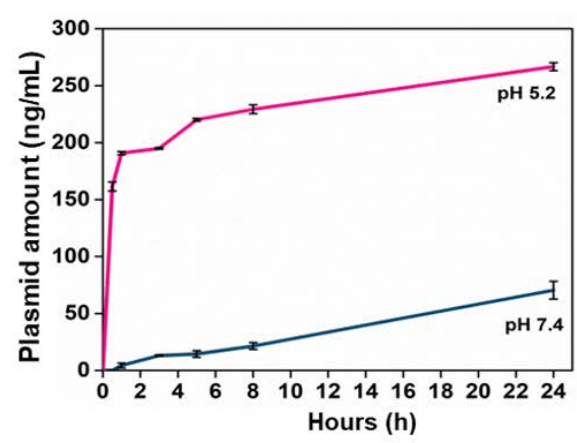

Figure S5. (A) Standard curve of CrhTERT plasmid concentration (B) pH-dependent release of CrhTERT@ZIF-C at pH 7.4 and pH 5.2 for 24 h. 


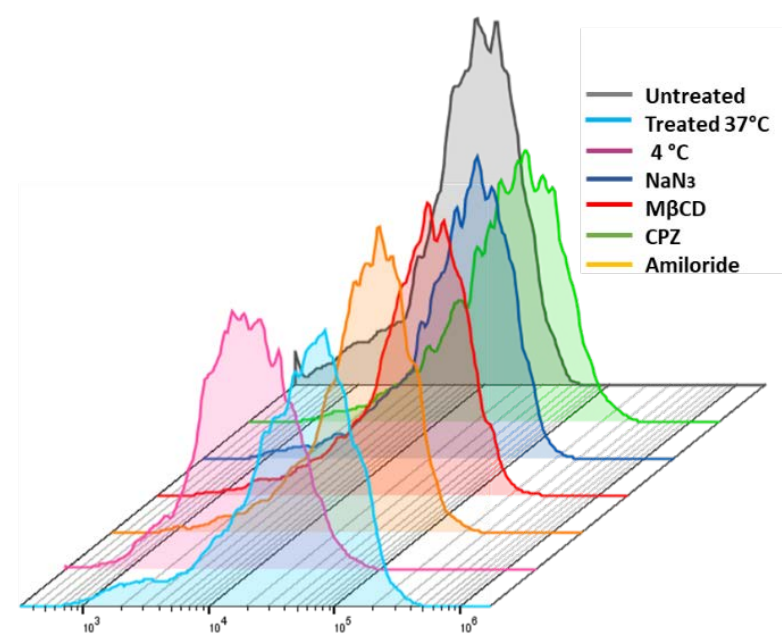

FL1A

Figure S6. Study on the mechanism of cellular uptake of CrhTERT@ZIF-C in PC-3 cells by flow cytometry. The cells were pretreated at $4^{\circ} \mathrm{C}$ or with diverse inhibitors at $37^{\circ} \mathrm{C}$ for $0.5 \mathrm{~h}$, and then cotreated with CrhTERT@ZIF-C for 6 h. The cells without treatment were used as control. CrhTERT@ZIF-C were synthesized using $3 \mu \mathrm{g}$ of YOYO-1 labelled plasmid.

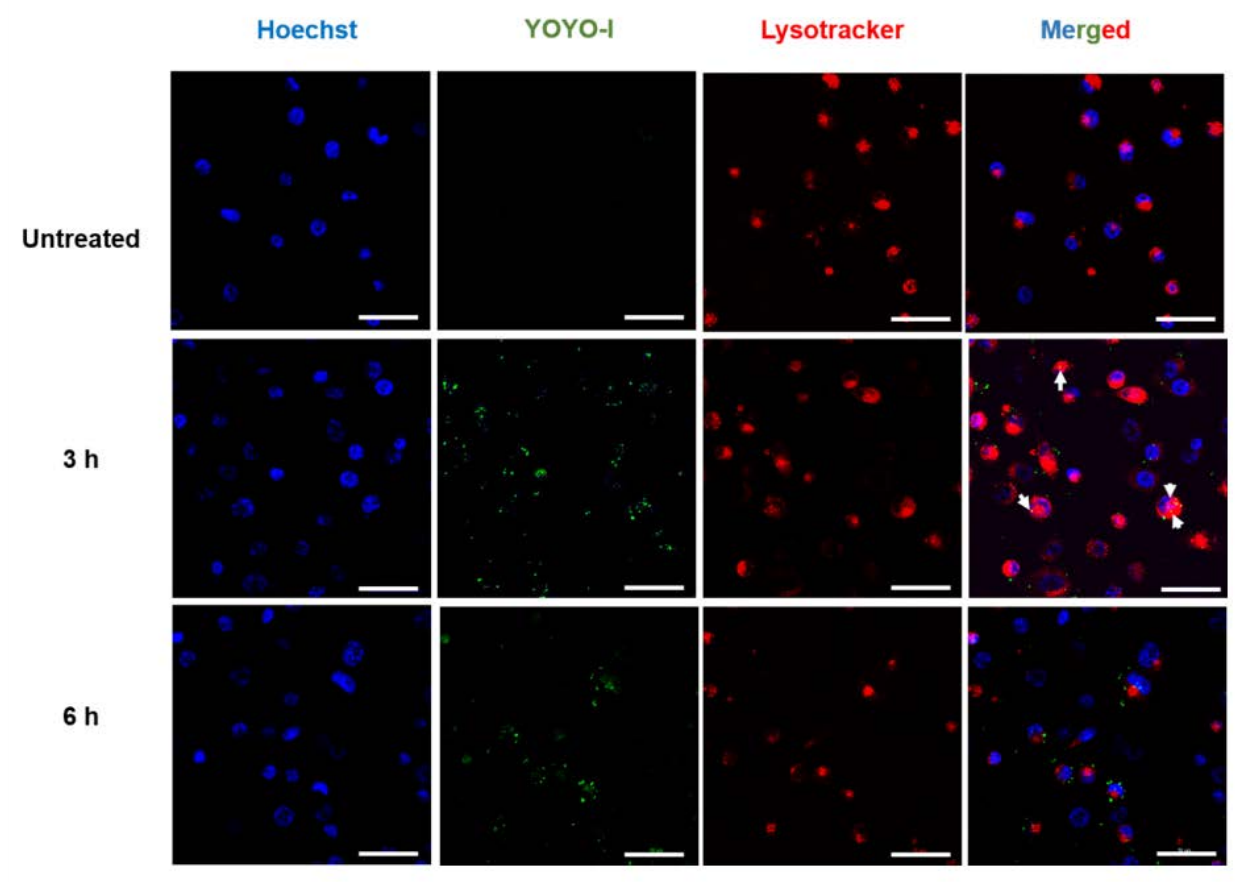

Figure S7. Subcellular localization of CrhTERT in PC-3 cells after incubation for $3 \mathrm{~h}$ and $6 \mathrm{~h}$. Blue fluorescence represents the nucleus, green fluorescence represents Y-CrhTERT@ZIF-C, and red fluorescence represents endosomes. Scale bars $50 \mu \mathrm{m}$. 

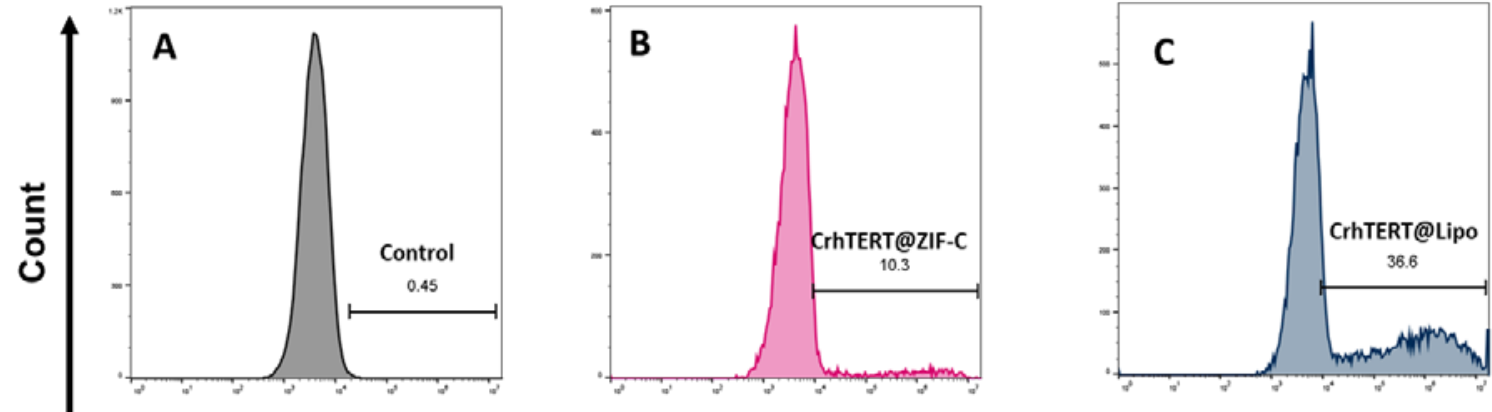

FL2-A

Figure S8. Transfection in PC-3 cells. (A-C) Transfection efficiency by flow cytometry (D) Untreated cells (E)CrhTERT@ZIF-C treated cells (F) CrhTERT complexed with lipofectamine reagent. All transfections were carried out for $96 \mathrm{~h}$ with $3 \mu \mathrm{g}$ of CrhTERT. Orange fluorescence due to protein expression from CrhTERT.

\section{References}

1. A. Poddar, S. Pyreddy, F. Carraro, S. Dhakal, A. Rassell, M. R. Field, T. S. Reddy, P. Falcaro, C. M. Doherty and R. Shukla, Chemical Communications, 2020, 56, 15406-15409.

2. E. Astria, M. Thonhofer, R. Ricco, W. Liang, A. Chemelli, A. Tarzia, K. Alt, C. E. Hagemeyer, J. Rattenberger, H. Schroettner, T. Wrodnigg, H. Amenitsch, D. M. Huang, C. J. Doonan and P. Falcaro, Materials Horizons, 2019, 6, 969-977. 